TI 2017-091/VII

Tinbergen Institute Discussion Paper
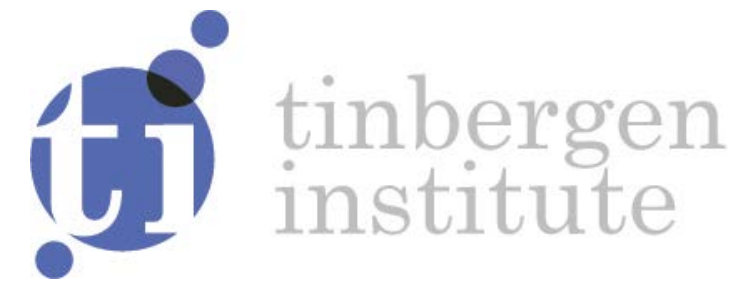

\title{
Banking Panics and Liquidity in a Monetary Economy
}

\section{Tarishi Matsuoka ${ }^{1}$}

Makoto (M.) Watanabe ${ }^{2}$

${ }^{1}$ Tokyo Metropolitan University, J apan

${ }^{2}$ VU Amsterdam; Tinbergen Institute, The Netherlands 
Tinbergen Institute is the graduate school and research institute in economics of Erasmus University Rotterdam, the University of Amsterdam and VU University Amsterdam.

Contact: discussionpapers@tinbergen.nl

More TI discussion papers can be downloaded at http://www.tinbergen.nl

Tinbergen Institute has two locations:

Tinbergen Institute Amsterdam

Gustav Mahlerplein 117

1082 MS Amsterdam

The Netherlands

Tel.: +31(0)205984580

Tinbergen Institute Rotterdam

Burg. Oudlaan 50

3062 PA Rotterdam

The Netherlands

Tel.: +31(0)10408 8900 


\title{
Banking Panics and Liquidity in a Monetary Economy*
}

\author{
Tarishi Matsuoka ${ }^{\dagger} \quad$ Makoto Watanabe ${ }^{\ddagger}$
}

September 8, 2017

\begin{abstract}
This paper studies banks' liquidity provision in the Lagos and Wright model of monetary exchanges. With aggregate uncertainty we show that banks sometimes exhaust their cash reserves and fail to satisfy their depositors' need of consumption smoothing. The banking panics can be eliminated by the zero-interest policy for the perfect risk sharing, but the first best can be achieved only at the Friedman rule. In our monetary equilibrium, the probability of banking panics is endogenous and increases with inflation, as is consistent with empirical evidence. The model derives a rich array of non-trivial effects of inflation on the equilibrium deposit and the bank's portfolio.
\end{abstract}

Keywords: Money Search, Monetary Equilibrium, Banking panic, Liquidity

JEL Classification Number: E40

\footnotetext{
${ }^{*}$ We thank Pedro Gomis-Porqueras, Todd Keister, Randy Wright, and participants at the 2017 Summer Workshop on Money, Payments, Banking and Finance held at the Bank of Canada for useful feedbacks. We also thank for his helpful comments and suggestions. This research was supported by JSPS KAKENHI Grant Number JP17K13703.

${ }^{\dagger}$ JSPS Overseas Research Fellow, Tokyo Metropolitan University, Address: Faculty of Urban Liberal Arts, Tokyo Metropolitan University, 1-1, Minami-Osawa, Hachioji, Tokyo, Japan 192-0397, Email: tarishi727@gmail.com

${ }^{\ddagger}$ VU Amsterdam, Tinbergen Institute, Address: Department of Economics, VU Amsterdam, De Boelelaan 1105, NL-1081 HV Amsterdam, The Netherlands, makoto.wtnb@gmail.com
} 


\section{Introduction}

This paper studies banks' liquidity provision in the Lagos and Wright (2005) economy of monetary exchanges. Our goal is to offer a monetary view on the implication of banking technologies à la Diamond and Dybvig (1983). We make explicit the role of money on the occurrence of banking fragilities. With aggregate uncertainty, we show that banks sometimes exhaust their cash reserves and fail to satisfy their depositors' need of consumption smoothing in monetary equilibria.

Our starting point is to realize that, in the spirit of Kiyotaki and Wright $(1989,1991)$, the essential role of money emerges due to market frictions where agents face idiosyncratic consumption opportunities (which causes a well-known double coincidence of wants problem). Given their uncertain consumption needs, agents can be benefited from a liquidity pool or demand deposits of banks that are callable in case they wish to consume and need money for the purchase. In case such an immediate need of money does not emerge, agents can use credit backed by their capital claim and receive its matured return.

More specifically, we extend a monetary model of banking by Williamson (2012) to allow for aggregate uncertainty. Just like in Williamson, a meeting in decentralized market can be either non-monitored, where money is needed for payment, or monitored, where other payment instruments can be used as well. Hence, the idiosyncratic need of money motivates the role of banks to provide liquidity insurance. In this paper, we introduce aggregate uncertainty about the fraction of the non-monitored exchange into his model, and hence about the total demand for money. Unlike in Williamson, we show that there are states in which banks exhaust their cash reserves and suspend convertibility of deposits into cash, called a banking panic.

Our monetary equilibrium with bank deposits has the following properties. On one hand, banking panics occur more often with higher proportions of the non-monitored exchanges or with lower bank money reserves. On the other hand, banking panics generate liquidity premia, where buyers who are engaged in non-monitored exchanges are forced to consume lower amounts compared to those in monitored exchanges. These are the senses in which we view banking panics as a monetary phenomenon. 
In our theory, a banking panic is an event of bank reserve shortage and suspensions of convertibility instead of banking insolvency, just like in Champ, Smith, and Williamson (1996) and many others. As Calomiris and Gorton (1991) put; "a banking panic occurs when bank debt holders at all or many banks in the banking system suddenly demand that banks convert their debt claims into cash (at par) to such an extent that the banks suspend convertibility of their debt into cash" (p.112). One example of the aggregate uncertainty in our setup is seasonal variations. In an agricultural economy, since workers have to be paid at harvest and crops have to be shipped before crop revenue is materialized, the aggregate demand for money is high at harvest season. Thus, large seasonal pressures can cause a banking panic. This view is consistent with the evidence that a banking panic tended to occur during the fall and spring in the U.S. during the National Banking Era (e.g., Sprague, 1910; Miron, 1986; Champ, Smith, and Williamson, 1996). Another example is a credit collapse. Fear of counterparty defaults due to pessimism would prevent people from trading with credit.

The bank's portfolio choice takes into account that money has a lower rate of return and is more liquid than capital. Given the rate of return dominance of capital, banks invest a positive fraction of their deposits in capital. In addition, expecting the trade opportunities where their depositors can use credit backed by capital claim, banks do not hold enough money to satisfy their depositors' liquidity needs in any possible state. This leads to a positive probability of banking panics. With the-zero-interest policy, which is not associated with the Freedman rule, the rate of return dominance disappears, and so banks hold all their deposits as money. In this situation, banks have enough money reserves to guarantee for sure their depositors with perfect consumption smoothing - a banking panic will never occur. This allocation is, however, below the efficient level. The latter distortion can be eliminated only at the Friedman rule, as usual, where money holding costs disappear.

Our model generates an endogenous dependence of the probability of banking panics on inflation. Empirical studies show that banking panics and inflation are positively correlated (e.g., Demirguc-Kunt and Detragiache, 1998, 2005; Hardy and Pazarbasioglu, 1998; Boyd et al., 2014). In particular, this positive correlation is more prominent in developing and emerging 
market economies than in developed countries (Joyce, 2010; Duttagupta and Cashin, 2011; Davis, Karim, and Liadze, 2011). Our theoretical prediction is consistent with it.

Finally, our model offers a rich array of non-trivial effects of inflation. For example, we show that the effect of inflation on the deposit level depends on the risk aversion parameter. When the risk aversion is low, agents reduce deposits as inflation gets higher. When the risk aversion is high, agents attempt to mitigate the consumption inequality between non-monitored and monitored meetings by increasing the entire resources transferred to future periods, and so the deposit increases with inflation. The risk aversion also matters for the effect of inflation on the banks' portfolio choice. There are two economic forces at work. On one hand, an increase in the inflation rate induces banks to shift their resources from money to capital. One the other hand, the total size of deposit determines the level of both of the assets. These potentially conflicting effects lead to a non-monotonic relationship between inflation and the bank's equilibrium portfolio, which is hard to obtain in other models.

In the literature of micro-founded money, some papers study money and collateralized credit or claims backed by capital or capital as a medium of exchange (e.g., Lagos and Rocheteau, 2008, Ferraris and Watanabe, 2008, 2012, and Gu, Mattesini, and Wright, 2016), and others study banking and credit (e.g., Berentsen, Camera, and Waller, 2007, Ferraris and Watanabe, 2008, 2011, Bencivenga and Camera, 2011, and Gu, Mattesini, and Wright, 2013) but these papers do not address the issue of banking panics. Among the papers which study banking and liquidity, Williamson (2012) is the closest to ours. The cases in which a banking panic does not occur, which happen with a subset of parameter space in our model, has essentially the same property as in his model. Our innovation is to generalize his banking problem to allow for the cases in which a banking panic occurs, and to show that such a case can indeed survive in a monetary equilibrium with aggregate money-demand uncertainty, even with the endogenous choice of the banks' cash reserve ratio and the depositors' deposit level. In a recent attempt, Andolfatto, Berentsen and Martin (2017) study financial stability, but with a very different approach. In their paper, a banking panic is modeled as a banking insolvency, which occurs because of sunspots, whereas in our model it is modeled as banks' reserve shortages 
and suspension of compatibility. Also, the probability of a panic is sunspot driven and is an exogenous constant in their model, while it is endogenous and is influenced by inflation in our model.

There is an extensive literature on liquidity, banking, and monetary policy using an OLG model with random relocation, such as Champ, Smith, and Williamson (1996), Antinolfi, Huybens, and Keister (2001), Smith (2002, 2003), Boyd, De Nicolo, and Smith (2004), Antinolfi and Keister (2006), Gomis-Porqueras and Smith (2003, 2006), Jiang (2008), and Matsuoka (2012), and with the nominal bank deposit contracts and a short-horizon economy such as Chang and Velasco (2000), Diamond and Rajan (2006), Skeie (2008) and Allen, Carletti, and Gale (2014). While the definition of a banking panic and some of our results are related, our theory differs fundamentally from them in the notion of money, and the role of money to play in the provision of liquidity and in the occurrence of banking panics. Other non-monetary models of banking panics are, for examples, Wallace (1990), Allen and Gale (1998, 2004), Green and Lin (2003), Peck and Shell (2003), Andolfatto, Nosal, and Wallace (2007), Andolfatto and Nosal (2008), and Ennis and Keister (2006, 2009, 2010).

The rest of the paper is organized as follows. Section 2 describes the model environment, Section 3 derives the monetary equilibrium with bank deposits and studies its dependence on inflation and the monetary policies. Section 4 discussed the model's implications to historical episodes and empirical evidence. Section 5 concludes. The appendix contains all proofs.

\section{Environment}

The model builds on a version of Lagos and Wright (2015). Time is discrete and continues forever. Each period is divided into two subperiods, called day and night. A market is open each subperiod. There are two types of a $[0,1]$ continuum of infinitely-lived agents. Agents of the same type are homogeneous. One type of agents, called sellers, have the production technology during the day, which allows to produce a perishable and divisible good, referred to as a special good. The other type of agents, called buyers, do not have the production 
technology during the day but can consume the special goods. Other divisible goods, referred to as a general good, are produced and consumed during the night. There is also an intrinsically worthless good, which is perfectly divisible and storable, called fiat money. Agents discount future payoffs at a rate $\beta \in(0,1)$ across periods, but there is no discounting between the two subperiods.

We assume that the instantaneous utility function for buyers and sellers are given by $u\left(q^{b}\right)+U(x)-h$ and $-q^{s}+U(x)-h$, respectively, where $q^{b}$ represents a buyer's consumption of special goods, and $q^{s}$ a seller's production of special goods. We assume constant marginal production costs and that the utility function $u(q)$ is strictly increasing, strictly concave, and twice continuously differentiable function with $u(0)=0, u^{\prime}(0)=\infty, u^{\prime}(\infty)=0$, and with the property that there exists some $\hat{q}>0$ such that $u(\hat{q})=\hat{q}$. For analytical tractability, we assume $\xi \equiv-\frac{q u^{\prime \prime}(q)}{u^{\prime}(q)}$ is a positive constant. If an agent consumes $x$ general goods then his utility is given by $U(x)$. We assume that $U(x)$ is strictly increasing, concave, and twice continuously differentiable.

During the day, buyers and sellers can trade special goods in decentralized markets (DM), which involves bilateral random matching. Just like in Williamson (2012) (see also Section 5 of Williamson and Wright, 2010), we assume that in the DM, there are a fraction $\alpha \in(0,1)$ of sellers who are engaged in a non-monitored exchange and a fraction $1-\alpha$ of sellers who are engaged in a monitored exchange. At the beginning of the day, sellers meet with their counterparts and buyers learn whether they will trade with sellers in non-monitored or monitored meetings. In the DM, exchanges are anonymous and trading histories are private knowledge. Therefore, in the non-monitored exchanges, claims to capital can be easily counterfeited, and so given the random meeting, sellers must receive money for immediate compensation of their products. In contrast, fake claims are confiscated for sure in the monitored exchange, and some credit deals are possible: buyers can promise credibly that they will make a payment to sellers later during the night. We will be specific about it shortly below. That individual buyers face the randomness in different needs of the medium of exchange plays a role of a "liquidity preference shock." This is similar in the spirit to Diamond and Dybvig (1983) to 
motivate the banks' risk sharing role. In any meeting, we assume for simplicity that buyers make a take-it-or-leave-it offer to sellers.

We assume that the fraction of monitored/non-monitored meetings is a random variable. It is publicly observable and identically distributed over time. Let $F=F(\alpha)$ represent the distribution function, which is assumed to be continuous, differentiable and strictly increasing, and $f=f(\alpha)>0$ the associated density function. As mentioned earlier, this randomness can be interpreted as a seasonal fluctuation or a credit-system collapse, and will play the key role in our model.

During the night, general goods are traded in the centralized market $(\mathrm{CM})$, which is Walrasian. There are two more economic activities during the night. First, buyers can access to a storage technology whereby one unit of the general goods stored, called capital, generates $R>1$ units of general goods in the next period. The return should satisfy $\beta R \leq 1$ since otherwise the solution would explode. Capital is not mobile and, as mentioned above, its claims can be costlessly counterfeited in the DM. Second, agents form banks in the CM. A bank offers a deposit contract to each of its depositors which stipulates a repayment plan as specified below. The depositors are buyers who deposit general goods in the CM and are in need of money and/or capital in the following DM. The bank stocks $m$ money and $k$ capital in the CM. Any credit contracts in the DM are settled in the CM of the same period.

Money is issued by the central bank. Let $M$ denote the stock of money available in a period, and it grows (or shrinks) at a constant rate $\pi$, i.e., $M_{+1}=\pi M$, through injection to (or withdraw from) the buyers in a lump-rum manner in the CM, where the subscript +1 stands for the next period. Denote by $\phi$ the price of money in terms of general goods. Then, we consider the rate of return of money dominated by the other asset, capital:

$$
\frac{\phi_{+1}}{\phi}<R
$$

Finally, money market clears each period so that the return of money must be equal to the inverse of the inflation rate, $\frac{\phi_{+1}}{\phi}=\frac{1}{\pi}$.

The first-best solution in our economy is straightforward. The socially optimal level of capital, denoted by $k^{*}$, is indeterminate if $\beta R=1$, and is given by $k^{*}=0$ if $\beta R<1$. The 
socially optimal levels of consumption, denoted by $q_{b}^{*}, q_{s}^{*}$, are given by $q_{b}^{*}=q_{s}^{*}=q^{*} \equiv u^{-1 \prime}(1)$, i.e, the marginal utility of special goods consumption $\left(=u^{\prime}\left(q^{*}\right)\right)$ equals to the marginal cost $(=1)$.

\section{Monetary Equilibrium}

\subsection{Banks' payment schedule}

We start with the banks' optimal repayment plan. First of all, since banks can do anything that buyers can do, there is no loss of generality in assuming that during the night, buyers deposit their entire general goods that they want to bring to a next period. Let $d$ denote the amount of general goods a buyer deposits in a representative bank. Note that even though there is aggregate uncertainty in our infinite horizon problem, the buyers deposit the same quantity each period given the Lagos-Wright formulation of the quasi-linear utility in the CM (see below).

At the beginning of a day, before buyers learn the type of their meeting, banks choose a payment schedule given their holdings of cash $m$ and capital $k$ selected in the previous CM (see below). The payment can be contingent on the realized aggregate state. Denote by $q^{n}=q^{n}(\alpha)$ $\left(q^{m}=q^{m}(\alpha)\right)$ the payment to a non-monitored (monitored) buyer. Let $\theta=\theta(\alpha)$ denote the fraction of its cash reserves that a bank pays out to non-monitored buyers. Given values of $m$ and $k$, and the bank's balance sheet constraint,

$$
\phi m+k=d,
$$

a bank's optimal choice of $\theta$ and individual claims, $c=c(\alpha)$, will imply the optimal $q^{n}$ and $q^{m}$. We assume competitive banks with free entry, each maximizes the expected value of its representative depositor (i.e. buyer), net of the total debt payment, $(1-\alpha) c$, measured in terms of general goods. Hence, given realized values $\alpha \in(0,1)$, a bank's problem in the DM can be written as:

$$
\max _{\theta \in[0,1], c \geq 0} \alpha u\left(q^{n}\right)+(1-\alpha)\left(u\left(q^{m}\right)-c\right)
$$


subject to

$$
\begin{aligned}
\alpha q^{n} & =\theta m \phi_{+1}, \\
(1-\alpha) q^{m} & =(1-\theta) m \phi_{+1}+(1-\alpha) c \\
(1-\alpha) c & \leq R k .
\end{aligned}
$$

(1) states that each individual non-monitored buyer receives $\frac{\theta m}{\alpha}$ units of cash from the bank and, given take-it-or-leave-it offers, exchanges it with the matched seller for $\frac{\theta m \phi_{+1}}{\alpha}$ units of special goods. (2) states similarly that the total real payment to monitored buyers equals to the bank's remaining cash reserves plus the total amount of credit, $(1-\alpha) c$, where $c$ is the capital claim that each individual monitored buyer receives. (3) is the credit constraint which states that the bank's capital $k$ can back in total the funding up to the limit equal to the real value in the following night, $R k$.

Discussion. The above bank's problem features different depositors' needs of different liquid assets. It may be useful to clarify a couple of issues here. First, one interpretation of the credit constraint (3) is that the debt of each individual monitored buyer, $c$, to the seller cannot exceed the real value of its capital holdings, $R \frac{k}{1-\alpha}$. In monitored exchanges, fake claims cannot be made and so the individual buyers can use their capital as a collateral to promise their payment credibly to the sellers. Alternatively, one could also interpret it as bank credit whereby all the monitored claims are managed by the banks, each uses its capital as a collateral to promise the payment of the monitored buyers to the sellers. Then, each of the individual buyers makes a bank loan that cannot exceed the real value of the available bank capital. Indeed, our main insight will go though with any form of individual credit, or bank credit or even bank notes that can be used in monitored exchanges but not in non-monitored exchanges. Second, while not made explicit here, we could write down the incentive problem of depositors since the meeting type of individual depositors does not need to be observed by the bank. However, monitored buyers have no incentive to misrepresent their type because $q^{m} \geq q^{n}$, so do non-monitored buyers because the bank payment in the form of credit is useless for them in the DM (see the proof of Theorem 1). Hence, such an incentive constraint would never 
bind the optimal solution. Third, the usual suspension of convertibility is embedded in our setup that the available assets are already selected before the choice of payment. Observing the selected $m$ and $k$ the depositors understand that the bank has already committed not to liquidate assets beyond this level. Finally, since non-monitored and monitored buyers cannot trade with each other, there is no issue of the side-trading that may potentially achieve a superior allocation to the current bank arrangement.

The first order conditions are

$$
\begin{aligned}
u^{\prime}\left(q^{n}\right)-u^{\prime}\left(q^{m}\right) & \geq 0 \quad(\text { with }=\text { if } \theta<1) \\
u^{\prime}\left(q^{m}\right) & \geq 1 \quad\left(\text { with }=\text { if } c<\frac{R k}{1-\alpha}\right) .
\end{aligned}
$$

The first condition is about the choice of $\theta$ and shows two situations are possible. One is $\theta<1$ which implies $q^{n}=q^{m}$, i.e., consumption smoothing. The other is $\theta=1$ which implies that the bank exhausts all the cash reserves and fails to achieve consumption smoothing, $q^{n}<q^{m}$. We refer to such an event as a banking panic. The second condition is about the choice of $c$ and shows that the monitored allocation $q^{m}$ can be the first best, $q^{*}=u^{-1 \prime}(1)$, when capital is abundant to offer enough credits.

Let $\gamma=\frac{\phi m}{d}$ denote the ratio of bank's cash reserves to deposits. Since $\gamma$ is chosen earlier in the previous $\mathrm{CM}$, the optimal solution to the bank's problem can be stated in terms of $\alpha$, $d$, and $\gamma$, with applying $m=\frac{\gamma d}{\phi}, k=(1-\gamma) d$ and $\frac{\phi_{+1}}{\phi}=\frac{1}{\pi}$, as summarized in the following proposition.

Theorem 1 (Bank's Payment Plan) Define the following critical values:

$\alpha_{A B} \equiv 1-\frac{R(1-\gamma)}{\frac{q^{*}}{d}}, \quad \alpha_{B C} \equiv \frac{\gamma}{\gamma+(1-\gamma) R \pi}, \quad \alpha_{A D} \equiv \frac{\gamma}{\frac{\pi q^{*}}{d}}, \quad \gamma_{C D} \equiv \frac{R \pi-\frac{\pi q^{*}}{d}}{R \pi-1}, \quad \gamma_{0} \equiv \frac{\pi q^{*}}{d}$.

Given $\alpha \in(0,1), d>0$ and $\gamma \in[0,1]$, the bank's optimal choice of payment plan $\left(q^{n}, q^{m}\right) \leq q^{*}$ is described as:

- Region A. for $\alpha>\max \left\{\alpha_{A B}, \alpha_{A D}\right\}$,

$$
q^{n}=\frac{\gamma d}{\alpha \pi}<q^{m}=q^{*}
$$


- Region B. for $\alpha \in\left[\alpha_{B C}, \alpha_{A B}\right]$,

$$
q^{n}=\frac{\gamma d}{\alpha \pi}<q^{m}=\frac{R(1-\gamma)}{1-\alpha}<q^{*}
$$

- Region C. for $\alpha \in\left[0, \alpha_{B C}\right)$ and $\gamma \geq \gamma_{C D}$,

$$
q^{n}=q^{m}=\left(\frac{\gamma}{\pi}+(1-\gamma) R\right) d<q^{*}
$$

- Region D. for $\alpha \in\left[0, \alpha_{A D}\right]$ and $\gamma \leq \min \left\{\gamma_{C D}, \gamma_{0}\right\}$,

$$
q^{n}=q^{m}=q^{*}
$$

The outcomes are illustrated in Figure 1. For low realizations of $\alpha$ or high reserve ratios $\gamma$, corresponding to Region $\mathrm{C}$ and $\mathrm{D}$, the bank has enough cash reserves relative to the cash need of their depositors. In these regions, the bank pays out only a fraction of its reserves to the non-monitored buyers, i.e., $\theta<1$ and the depositors receive the same payment irrespective of the type of meetings, enjoying consumption smoothing. Hence, the bank offers the perfect risk sharing service. In Region $\mathrm{D}$, the trades are efficient, i.e., $q^{n}=q^{m}=q^{*}$. In particular, when $\gamma=\gamma_{0}$ the trades are done with cash only, that is, the bank holds the reserves just to cover the DM consumption, $\phi_{+1} m=q^{*}$. Note that when $\gamma=1$, consumption smoothing is achieved for any realized state. For higher values of $\alpha$ or lower values of $\gamma$, the reserves is tighter relative to the depositors' needs. In Region A and B, even though all the reserves are paid out to the non-monitored buyers, i.e., $\theta=1$, the non-monitored buyers receive a lower payment than the monitored buyers do, $q^{n}<q^{m}$, thereby the consumption smoothing fails. Hence, the risk sharing does not work perfectly here. In these regions, no money is left to the monitored buyers and so payments to the monitored buyers are drawn from the capital claims. In particular, in Region A, while each monitored exchange is efficient, $q^{m}=q^{*}$, the total volume of monitored exchanges, $(1-\alpha) q^{m}$, is so low that part of the available credit prepared for the monitored-buyers is left unused. Since in this region $\alpha$ is very high or $\gamma$ is very low, each non-monitored buyer receives a very low payment, leading to a very big difference in the consumption levels. Note that the total deposit size also matters: Region D disappears 


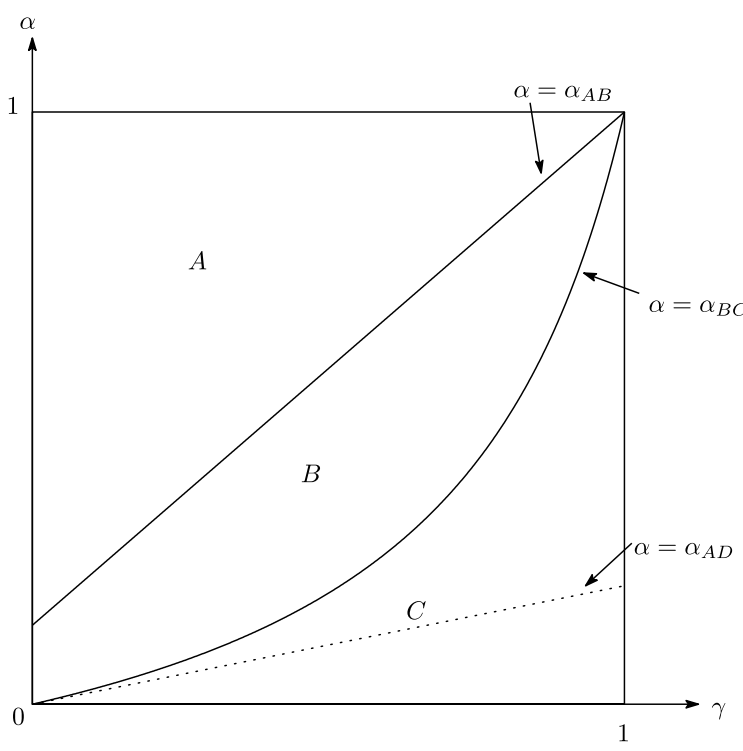

(a) $0<d \leq \frac{q^{*}}{R}$

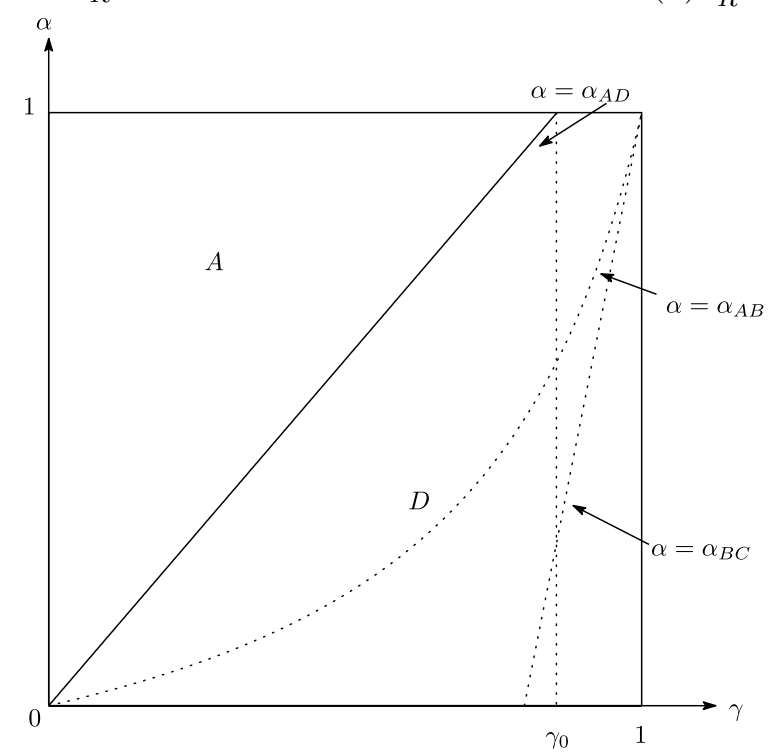

(c) $d>\pi q^{*}$

Fig 1: Bank's Payment Plan 
when $d \leq \frac{q^{*}}{R}$ while Region B and C disappear when $d \geq \pi q^{*}$. The three upward-sloping curves that divide regions meet $\alpha_{A B}=\alpha_{B C}=\alpha_{A D} \in(0,1)$ at $\gamma=\gamma_{C D} \in(0,1)$.

As mentioned earlier, the characteristics of a banking panic in this model are consistent with the Calomiris and Gorton's definition. This definition aims at capturing the situation where a significant number of depositors suddenly demand to redeem bank debt for cash, leading to a shortage of the overall amount of reserves in the banking system and a suspension of convertibility. The analysis here has high relevance to the panics under the National Banking Era in the U.S. (1863-1913) and the recent Greek panic in 2015.

\subsection{Monetary equilibrium with bank deposits}

We now establish a stationary monetary equilibrium with bank deposits by deriving the bank's optimal portfolio and the buyers' optimal deposit. Our main interest lies in whether a banking panic as described by the Region A or B above can occur with aggregate uncertainty.

Given values of $d$ and the repayment plan described in Theorem 1, the bank chooses the reserve ratio $\gamma$ in the CM. Denote by $\gamma(d)$ the optimal solution. The bank's objective function differs depending on values of $d$. For $d \leq \pi q^{*}$, we have two cases. Suppose that $\gamma=\gamma(d) \geq \gamma_{C D}$. Then, since $d \leq \frac{q^{*}}{R} \Longleftrightarrow \gamma_{C D} \equiv \frac{\pi R-\frac{\pi q^{*}}{d}}{\pi R-1} \leq 0$, we are in Figure 1 (a) and the right half of Figure 1 (b), i.e., we are in either Region A, B or C, depending on values of $\alpha$. Hence, the bank's problem can be written as

$$
\begin{aligned}
\tilde{V}(d \mid \gamma) & =\max _{\gamma \in\left[\gamma_{C D}, 1\right]} \int_{\alpha_{A B}}^{1}\left[\alpha u\left(q^{n}\right)+(1-\alpha)\left\{u\left(q^{*}\right)+W\left(k^{\prime}, q^{*}\right)\right\}\right] f(\alpha) d \alpha \\
& +\int_{\alpha_{B C}}^{\alpha_{A B}}\left[\alpha u\left(q^{n}\right)+(1-\alpha)\left\{u(c)+W\left(k^{\prime}, c\right)\right\}\right] f(\alpha) d \alpha \\
& +\int_{0}^{\alpha_{B C}}\left[u\left(q^{n}\right)+(1-\alpha) W\left(k^{\prime}, c\right)\right] f(\alpha) d \alpha+\int_{0}^{1} \alpha W(0,0) f(\alpha) d \alpha
\end{aligned}
$$

where $W\left(k^{\prime}, c\right)$ is the expected value of a buyer who enters the CM with holdings of $k^{\prime}=\frac{(1-\gamma) d}{1-\alpha}$ capital and $c$ debt payment, as the bank capital is split equally among the monitored buyers. The first integral represents the expected utility of depositors in Region A, where $q^{n}=\frac{\gamma d}{\alpha \pi}$, $q^{m}=q^{*}$ and $c=q^{*}$, the second integral represents that in Region $\mathrm{B}$, where $q^{n}=\frac{\gamma d}{\alpha \pi}$ and 
$q^{m}=\frac{R(1-\gamma) d}{1-\alpha}$, and the third integral in Region C, where $q^{n}=q^{m}=d\left(\frac{\gamma}{\pi}+(1-\gamma) R\right)$. In the latter two regions, $c=\frac{R(1-\gamma) d}{1-\alpha}$. The critical value is $\max \left\{\alpha_{A B}, \alpha_{A D}\right\}=\alpha_{A B}$ and $\alpha_{B C}$.

Suppose next that $\gamma=\gamma(d)<\gamma_{C D}\left(=\min \left\{\gamma_{C D}, \gamma_{0}\right\}<1\right)$. Then, $\alpha_{B C}>\alpha_{A B}$ and so Region B is empty. Hence, we are in the left half of Figure 1 (b), i.e., we are in either Region A or D. The bank's problem can be written as

$$
\begin{aligned}
\tilde{V}(d \mid \gamma)= & \max _{\gamma \in\left[0, \gamma_{C D}\right]} \int_{\alpha_{A D}}^{1}\left[\alpha u\left(q^{n}\right)+(1-\alpha)\left\{u\left(q^{*}\right)+W\left(k^{\prime}, q^{*}\right)\right\}\right] f(\alpha) d \alpha \\
& +\int_{0}^{\alpha_{A D}}\left[u\left(q^{*}\right)+(1-\alpha) W\left(k^{\prime}, c\right)\right] f(\alpha) d \alpha+\int_{0}^{1} \alpha W(0,0) f(\alpha) d \alpha .
\end{aligned}
$$

The first integral represents the expected utility of depositors in Region A, as stated before, and the second integral represents that in Region D, where $q^{n}=q^{m}=q^{*}$ and $c=\frac{q^{*}-\frac{\gamma d}{\pi}}{1-\alpha}>0$. The critical value is $\max \left\{\alpha_{A B}, \alpha_{A D}\right\}=\alpha_{A D}$. The non-monitored buyer has no capital and no debt claim and so the night-time value of non-monitored buyers is always given by $W(0,0)$ as is summarized in the last term.

For $d>\pi q^{*}$, we are in Figure 1 (c), i.e., either Region A or D. This case is relatively simple because by setting $\gamma=\gamma_{0}<1$ the bank can guarantee that $q^{n}=q^{m}=q^{*}$ with no use of capital claim for any realized values of $\alpha \in[0,1]$. Hence, for $d>\pi q^{*}$, the bank's optimal solution is $\gamma^{*}=\gamma_{0}\left(\Longleftrightarrow \phi_{+1} m=q^{*}\right)$.

We now specify the night time value, $W(\cdot)$. In the $\mathrm{CM}$, buyers produce and consume general goods, invest in capital and settle the payment they have promised during the day (if any). The expected value of a buyer entering the night market in a given period with holdings $k^{\prime}$ of capital and $c$ debt from the DM, denoted by $W\left(k^{\prime}, c\right)$, satisfies

$$
\begin{aligned}
W\left(k^{\prime}, c\right)= & \max _{x, h, d_{+1} \geq 0} U(x)-h+\beta V\left(d_{+1}\right) \\
\text { s.t. } & x+d_{+1}+c=h+R k^{\prime}+\phi T,
\end{aligned}
$$

and the usual non-negativity constraints, where $T$ denotes the monetary transfers (or taxes), and $V\left(d_{+1}\right)$ the expected value in the next DM with deposits $d_{+1}$. Note that it is the job of banks to use these resources to stock money and capital during the night, which we will describe in detail later. 
Substituting out $h$, we obtain

$$
W\left(k^{\prime}, c\right)=R k^{\prime}+\phi T-c+\max _{x>0}\{U(x)-x\}+\max _{d_{+1}>0}\left\{-d_{+1}+\beta V\left(d_{+1}\right)\right\},
$$

implying that $d_{+1}$ is independent of wealth $R k^{\prime}+\phi T-c$. This is the usual property in the Lagos-Wright model. It is especially important to our model, because with aggregate uncertainty the buyer's debt payment $c$ is contingent on the realization of aggregate state but thanks to this property, the choice of deposit each period does not depend on the distribution of $c$. The first-order condition yields the consumption of general goods $x^{*}=U^{-1 \prime}(1)$. The same solution applies to sellers who are passive in the CM and do not bring anything to the next period (since seller do not consume in the DM and do not have the storage technology).

We are now ready to solve the bank's portfolio choice problem. We prove in Appendix that there exists a unique solution, which is characterized as follows.

Theorem 2 (Bank's Portfolio Choice) The bank's optimal reserve ratio is given by a unique value $\gamma(d) \in(0,1)$ for $d \leq \pi q^{*}$ and $\gamma(d)=\gamma_{0} \equiv \frac{\pi q^{*}}{d}$ for $d>\pi q^{*}$. Further, $\gamma(d)$ is monotone decreasing in $d$.

For $d \leq \pi q^{*}$, at the optimum, the marginal expected utility of depositors is set equal to the marginal cost of debt payment for their capital claim. The optimal solution should satisfy $\gamma(d)<1$ especially because with a higher cash-reserve rate, monitored buyers suffer from a reduction in the repayment at some realized states, and a reduction in the capital holdings. This leaves the possibility of banking panics. For $d>\pi q^{*}$, the bank has enough deposits to offer the sufficient liquidity to provide the efficient risk sharing and eliminate a banking panic. The negative dependence of $\gamma$ on $d<\pi q^{*}$ is because the bank cares more and more the rate of return dominance, $R>\frac{\phi_{+1}}{\phi}=\frac{1}{\pi}$, rather than the liquidity benefits, and on $d \geq \pi q^{*}$ simply reflects the size effects, given the fixed $\phi_{+1} m=q^{*}$.

The last step is to determine the optimal deposits of buyers, given the deposit contract offered by banks described above. A buyer's problem in the CM is

$$
\max _{d \in[0, \infty)}\{-d+\beta V(d)\}
$$


where $V(d)=\max _{\gamma \in[0,1]} \tilde{V}(d \mid \gamma)$ for $d \leq \pi q^{*}$ as derived above, and $V(d)=\hat{V}(d)$, which is the value for $d>\pi q^{*}$, where the efficient risk sharing is achieved with $\gamma=\gamma_{0}$, and is given by

$$
\hat{V}(d)=\int_{0}^{1}\left[u\left(q^{*}\right)+\alpha W(0,0)+(1-\alpha) W\left(\frac{\left(1-\gamma_{0}\right) d}{1-\alpha}, 0\right)\right] f(\alpha) d \alpha .
$$

Definition 1 A stationary monetary equilibrium with bank deposits is described by a price of money, $\phi>0$, a deposit $d>0$ satisfying (6), the bank's reserve ratio $\gamma(d)>0$ given in Theorem 2, and the repayment plan $\left(q^{n}, q^{m}\right) \leq q^{*}$ given in Theorem 1 .

As $\gamma=\gamma(d)$ is a monotone decreasing function of $d$, there exists a unique $\tilde{d} \in\left(\frac{q^{*}}{R}, \pi q^{*}\right)$ such that (see the proof of Proposition 1):

- for $d \in(0, \tilde{d}], \gamma(d) \in\left[\gamma_{C D}, 1\right)$ and its associated value $\tilde{V}(d \mid \gamma(d))$ is given by (4);

- for $d \in\left(\tilde{d}, \pi q^{*}\right], \gamma(d) \in\left(0, \gamma_{C D}\right)$ and its associated value $\tilde{V}(d \mid \gamma(d))$ is given by (5);

- for $d \in\left(\pi q^{*}, \infty\right), \gamma(d)=\gamma_{0} \equiv \frac{\pi q^{*}}{d}<1$ and its associated value $\hat{V}(d)$ is given by $(7)$.

For $d \in(0, \tilde{d}]$, the Euler equation is

$$
\frac{\pi}{\beta}=\int_{\alpha_{B C}}^{1} u^{\prime}\left(\frac{\gamma d}{\alpha \pi}\right) f(\alpha) d \alpha+u^{\prime}\left(d\left(\frac{\gamma}{\pi}+R(1-\gamma)\right)\right) F\left(\alpha_{B C}\right),
$$

with $\gamma=\gamma(d)$, while for $d>\tilde{d}$, we have

$$
V^{\prime}(d)=R
$$

wherever differentiable. It reflects the concavity of the value function $V(d)$ and the marginal value of deposit hits the lower bound $R$ for high values of $d$. The deposit choice is illustrated in Figure 2. We therefore have the following result.

Proposition 1 (Monetary Equilibrium with Bank Deposit) A monetary equilibrium with bank deposit exists.

- If $\beta R<1$, there exists a unique outcome $d^{*} \in(0, \tilde{d})$ with $\tilde{d} \in\left(\frac{q^{*}}{R}, \pi q^{*}\right)$, where a banking panic occurs with positive probability. It satisfies $\gamma(d) \in\left(\gamma_{C D}, 1\right)>0$ and $q^{n}, q^{m} \leq q^{*}$ in Region $A, B$ or $C$. 


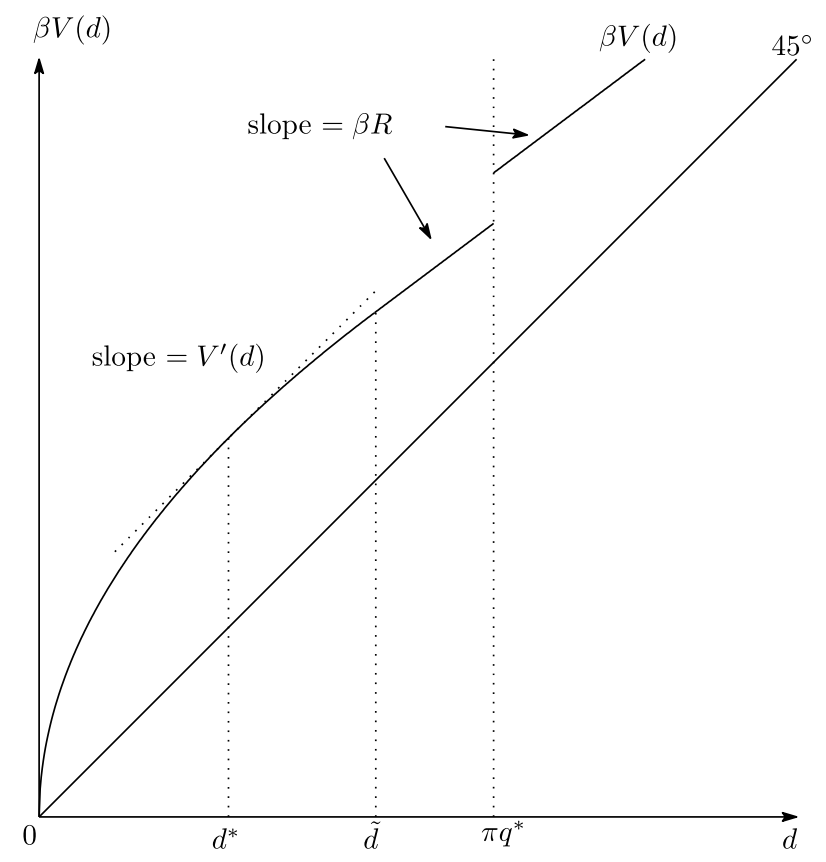

Fig 2: Deposit Choice when $\beta R<1$

- If $\beta R=1$, the equilibrium is indeterminate with any $d \in[\tilde{d}, \infty)$, featuring banking panics and the efficient risk sharing. In equilibria with $d \in\left[\tilde{d}, \pi q^{*}\right]$, they involve $\gamma(d) \in\left(0, \gamma_{C D}\right]$ and $q^{n}, q^{m} \leq q^{*}$ in Region $A$ or $D$, while in equilibria with $d>\pi q^{*}, \gamma(d)=\gamma_{0}$ and $q^{n}=q^{m}=q^{*}$ in Region D.

With aggregate uncertainty, the proposition shows that a banking panic can occur in equilibrium with positive probability if $\beta R<1$, and as one possible equilibrium outcome if $\beta R=1$. In the former case, the equilibrium is unique with relatively low deposits. With relatively high realizations of $\alpha$, the available amount of liquidities offered by banks is not enough to guarantee the consumption smoothing, leading to $q^{n}<q^{m}$ (Region A and B), while it is guaranteed with relatively low realizations of $\alpha, q^{n}=q^{m}<q^{*}$ (Region C). In other words, expecting that credit can be used as a payment with positive probability, banks do not pool enough liquidities to provide their depositors with the perfect risk sharing. A similar logic applies to the latter case with a continuum of equilibrium deposits that encompasses banking panics (Region A), which occur with low deposits, and the efficient risk sharing $q^{n}=q^{m}=q^{*}$ (Region D), which occurs with high deposits. 
The following proposition shows how the perfect risk sharing outcome and the efficient allocation can occur in our monetary equilibrium with bank deposit.

Proposition 2 (Risk sharing/Efficiency) Consider the monetary equilibrium with bank deposit and $\beta R<1$. The zero-nominal-interest-rate policy, $\pi \rightarrow \frac{1}{R}$, implements the perfect risk sharing, $q^{n}=q^{m}$, but the equilibrium allocations are efficient if and only if $\pi \rightarrow \beta$, at the Friedman rule.

The zero-nominal-interest-rate policy equates the rate of return of money and capital and so due to its liquidity benefit, banks hold their entire deposits as money, $\gamma(d) \rightarrow 1$. This allows them to offer the perfect risk sharing service to their depositors, yielding the consumption smoothing $q^{n}=q^{m}$. However, this payment is short of the efficient level, since given $\pi>\beta$, the choice of deposit level takes into account money holding costs, leading to $d<\frac{q^{*}}{R}$. The latter costs are eliminated only at the Friedman rule, where $d \rightarrow \frac{q^{*}}{R}$ as $\pi \rightarrow \beta$ yields the efficient risk sharing $q^{n}=q^{m} \rightarrow q^{*}$. The effects of inflation on the equilibrium outcomes are summarized as follows.

Proposition 3 (Effects of inflation) Consider the monetary equilibrium with bank deposit, $\beta R<1$ and $\xi \equiv-\frac{u^{\prime \prime}(q) q}{u^{\prime}(q)}<1$.

1. The bank cash reserve rate $\gamma$ is monotone decreasing in inflation.

2. The probability of banking panics is monotone increasing in inflation.

3. The equilibrium deposit level d is monotone decreasing in inflation when the risk aversion is low $\xi<\hat{\xi}$ and is monotone increasing in inflation when the risk aversion is high $\xi>\hat{\xi}$, with some critical value $\hat{\xi} \in(0,1)$.

4. Capital is monotone increasing in inflation when $\xi>\hat{\xi}$, and increases in low inflation and decreases in high inflation when $\xi<\hat{\xi}$.

5. Money holdings are monotone decreasing in inflation when $\xi<\hat{\xi}$, and increase in low inflation and decreases in high inflation when $\xi>\hat{\xi}$. 
$\xi<\hat{\xi}$

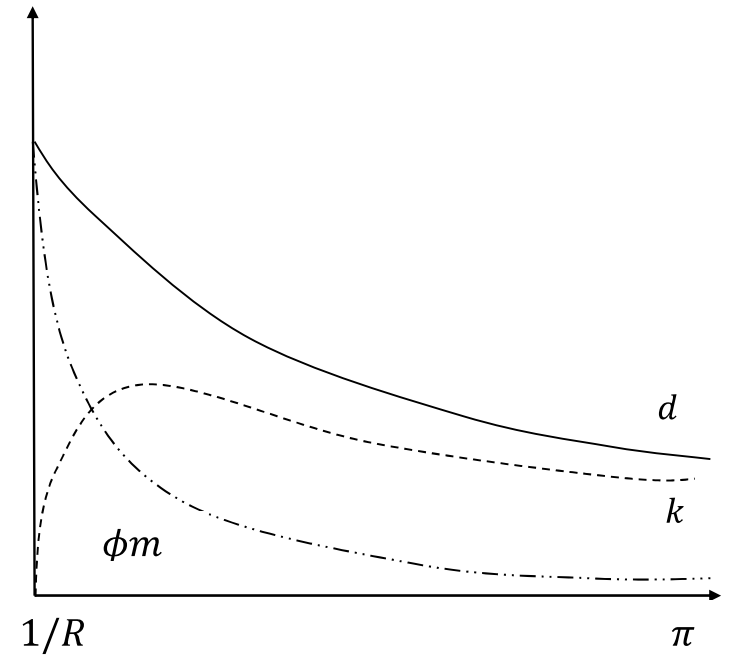

$\xi>\hat{\xi}$

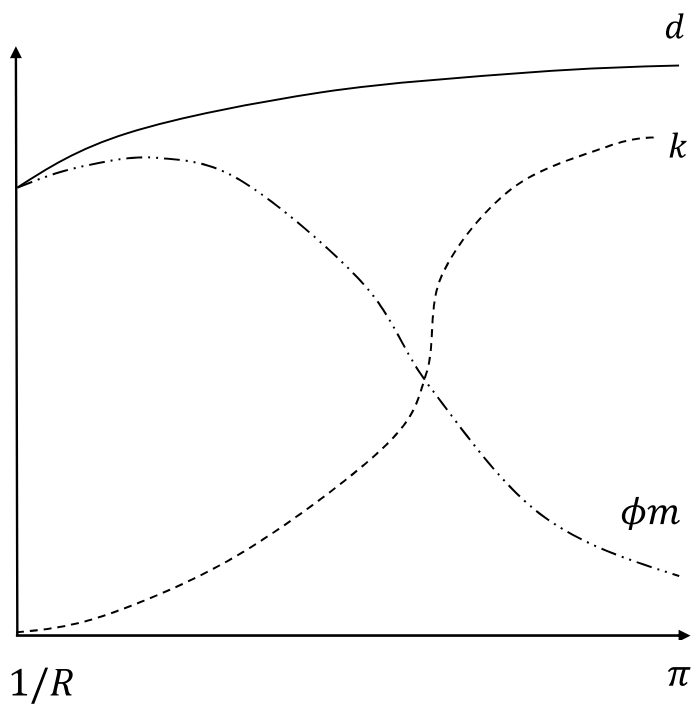

Fig 3: Equilibrium Deposit and Bank's Portfolio

The bank's equilibrium rate of cash-reserve $\gamma$ decreases with inflation, reflecting the usual increasing money holding costs. This leads to the positive effect of inflation on the probability of banking panics. The effect of inflation on the deposit level depends on the risk aversion parameter $\xi$. When $\xi$ is low, the equilibrium deposit level decreases with inflation. When $\xi$ is high, buyers care much about consumption smoothing. In this situation, buyers attempt to mitigate the consumption inequality between non-monitored and monitored meetings by increasing the entire resources transferred to future periods, and so the deposit increases with inflation. The risk aversion also matters for the effect of inflation on the banks' portfolio choice. There are two economic forces at work. On one hand, an increase in the inflation rate induces banks to shift their resources from money to capital. One the other hand, the total size of deposit determines the level of both of the assets. When $\xi$ is low, the former (latter) effect is dominant for low (high) inflation for the determination of capital holdings. Hence, capital investments are non-monotone in inflation. When $\xi$ is high, the latter (former) effect is dominant for low (high) inflation for the determination of money holdings. Hence, money holdings are non-monotone in inflation, which is had to obtain in other models. These results 
are summarized in Figure 3 and have not been reported by the existing literature on OLG models.

\section{Historical Backgrounds and Empirical Implications}

The following discussion provides historical backgrounds and empirical support for our key results.

First, we argue that some aspects of our model can be connected to historical banking panics during the National Banking Era and emerging market economies. According to Sprague (1910) and Chari (1989), there are two key features of the National Banking System in U.S. which played an important role in banking panics. One is that banks were not able to branch between states and issue notes freely, and the other is that banks were able to deposit their reserves in New York City banks at a high interest rate. The former implied that the banks could not diversify regional and seasonal liquidity risks, and the repayments had to be done by their own liquid reserves. The latter meant that there was a shortage of aggregate liquidity reserves in a whole banking system during panics since New York City banks invested these deposits into illiquid assets in order to earn the interest demanded. The committee appointed by the New York Clearing House Association in 1873 argued, "The aggregate [reserves] held by all the national banks of the United States does not finally much exceed 10 per cent of their direct liabilities, without reference to the large amount of debt which is otherwise dependent upon the same reserves" and "The abandonment of the practice of paying interest upon deposits will remove a great inducement to divide these reserves between cash in hand and deposits in cities, and make the banks throughout the country what they should always be, financial outposts to strengthen the general situation"(Sprague, 1910, p. 96-97). During the period from 1864 to 1933, there were seven economy-wide panics $(1873,1884,1890,1893$, 1907, 1930, and 1933), and four of them $(1873,1893,1907$, and 1933) led to large suspension of convertibility of deposits into currency.

The Argentina crisis of 2001 is also a relevant episode for our analysis (see Ennis and 
Keister, 2009). In the late 1990s, the Russian sovereign default leads Argentina's economy to a credit collapse and a deep recession. During November 28-30 in 2001, there was a panics, and many depositors rushed and tried to withdraw their funds from all banks simultaneously. Banks were under severe pressure from massive withdrawals, and the government declared that deposits are frozen for 90 days beginning on December 1. During this freeze, people were allowed to withdraw up to only 1,000 pesos per month from each account. The recent panics in Cyprus in 2013 and Greece in 2015 were quite similar since they also involved a shortage of currency and suspension convertibility. A suspension of convertibility (often called deposit freeze or banking holiday) is the common policy response to a panic even today.

Our model illustrates several important features of these episodes. First, a sudden aggregate currency demand (due to a seasonal variation and/or a credit collapse) cause a shortage of aggregate reserves, leading to a banking panic. Second, banks are restricted not to branching freely and using other repayment methods (e.g., bank notes); otherwise a panic can be eliminated like in the Canadian banking system during the National Banking Era. Third, convertibility of deposits into currency is often suspended during a panic. This paper has explored the nature of banking failures in an economy where currency is used as a medium of exchange.

Finally, we close this section by relating briefly our main results to empirical studies. There are much evidence, such as Demirguc-Kunt and Detragiache $(1998,2005)$, Hardy and Pazarbasioglu (1998), Joyce (2010), Duttagupta and Cashin (2011), Davis, Karim, and Liadze (2011), and Boyd et al. (2014), showing that a banking crisis and inflation are positively correlated. Gomis-Porqueras and Smith (2006) use data covering 1890-1913 during the National Banking Era and find that the reserve-deposit ratio decreases and the probability of a banking crisis increases as the nominal interest rate increases. These are consistent with our first two results of Proposition 3. In addition, the other three results (in the case of low $\xi$ ) implies the existence of a threshold effect about the relationship between inflation and real economic activities (investment and output). Bullard and Keating (1995), King and Watson (1997), Bruno and Easterly (1998), Ahmed and Rogers (2000), Crosby and Otto (2000), Khan and Senhadji 
(2001), Kremer, Bick, and Nautz (2013), among others, show that inflation has almost no (or slightly positive) effect on real economic activities (e.g., investment, output, and growth) when the inflation rate is low, but its impact becomes negative significantly when the inflation rate exceeds a certain threshold. Boyd, Levine and Smith (2001) and Khan, Senhadji, and Smith (2006) identify the inflation threshold in the relationship between inflation and financial market activities (bank lending activity and stock market development). Clearly, these evidence also support our results.

\section{Conclusion}

We studied banks' liquidity provision in the Lagos and Wright model of monetary exchanges. With aggregate uncertainty we showed that banks sometimes exhaust their cash reserves (banking panics) and fail to satisfy their depositors' need of consumption smoothing. The banking panics can be eliminated by the zero-interest policy, which equates the rete of return of two assets, money and capital, motivating banks to hold a sufficient amount of liquidities for the perfect risk sharing. However, the total amount of deposits is not enough for the equilibrium allocation to be efficient. This distortion can be eliminated only at the Friedman rule. In our monetary equilibrium, the probability of banking panics is endogenously determined. We find that this probability is increasing in the rate of inflation, as is consistent with empirical evidence. The model offers a rich array of non-trivial effects of inflation on the equilibrium deposit and the bank's portfolio.

The model is fairy tractable. We think that the following line of extensions will be interesting. First, after a liquidity shortage is realized, banks will be able to avoid a panic if the discount window lending were available unlimitedly for sure. This would in turn reduce the banks' ex ante incentive to hold liquid assets. We are therefore interested in whether such a central bank's policy distorts the banks' investment decision over assets with different returns and different liquidities, and induces them to invest in risky assets in the first place. Second, while a perfect interbank market should allow banks to reallocate liquidity ex post and hedge 
the liquidity risk completely, we can study whether an imperfect interbank market such as the one supported by repo contracts should reduce or facilitate banking panics. Finally, by assuming that capital can be scraped and the scraped capital can be used in the non-monitored exchange with hair cut, we could ask why some banking panics are associated with no output losses, but other panics cause serious recessions. 


\section{Appendix A}

\section{Proof of Theorem 1}

Applying $m=\frac{\gamma d}{\phi}$, we can write $q^{n}=\frac{\theta \gamma d}{\alpha \pi}$ and $q^{m}=\frac{(1-\theta) \gamma d}{(1-\alpha) \pi}+c$. Applying $k=(1-\gamma) d$, we get the Lagrangian function,

$$
\mathfrak{L}=\alpha u\left(\frac{\theta \gamma d}{\alpha \pi}\right)+(1-\alpha)\left[u\left(\frac{(1-\theta) \gamma d}{(1-\alpha) \pi}+c\right)-c\right]+\mu_{0}\{R(1-\gamma) d-(1-\alpha) c\}+\mu_{1} c+\mu_{2}(1-\theta),
$$

where $\mu_{0}, \mu_{1}, \mu_{2} \geq 0$ are the Lagrangian multipliers. Note that $\theta=0$, leading to $q^{n}=0$, cannot be a solution by the Inada condition. The first-order conditions are

$$
\begin{aligned}
& \frac{\partial \mathfrak{L}}{\partial \theta}=\frac{\gamma d}{\pi}\left(u^{\prime}\left(q^{n}\right)-u^{\prime}\left(q^{m}\right)\right)-\mu_{2}=0, \\
& \frac{\partial \mathfrak{L}}{\partial c}=(1-\alpha)\left[u^{\prime}\left(q^{m}\right)-1-\mu_{0}\right]+\mu_{1}=0 .
\end{aligned}
$$

Region A: $\theta=1$ and $c<\frac{R(1-\gamma) d}{1-\alpha}$. In this case, $\mu_{0}=0$ and since $\theta=1$, we must have $c>0$, implying $\mu_{1}=0\left(c=0\right.$, leading to $q^{m}=0$, cannot be a solution by the Inada condition $)$. Hence, by (A.2), $q^{m}=q^{*} \equiv u^{-1 \prime}(1)$. This further implies that

$$
c=q^{*}<\frac{R(1-\gamma) d}{1-\alpha} \Longleftrightarrow \alpha>1-\frac{R(1-\gamma) d}{q^{*}} \equiv \alpha_{A B} .
$$

On the other hand, (A.1) implies that $u^{\prime}\left(q^{n}\right) \geq u^{\prime}\left(q^{m}\right) \Longleftrightarrow q^{m}=q^{*} \geq q^{n}=\frac{\gamma d}{\alpha \pi} \Longleftrightarrow$

$$
\alpha \geq \frac{\gamma d}{\pi q^{*}} \equiv \alpha_{A D}
$$

Region B: $\theta=1$ and $c=\frac{R(1-\gamma) d}{1-\alpha}$. (A.1) implies that $u^{\prime}\left(q^{n}\right) \geq u^{\prime}\left(q^{m}\right) \Longleftrightarrow q^{m} \geq q^{n} \Longleftrightarrow$

$$
\alpha \geq \frac{\gamma}{\gamma+(1-\gamma) R \pi} \equiv \alpha_{B C}
$$

By (A.2) and $\mu_{1}=0$, we have $\alpha \leq \alpha_{A B}$.

Region C: $\theta<1$ and $c=\frac{R(1-\gamma) d}{1-\alpha}$. In this case, $\mu_{1}=\mu_{2}=0$. By (A.1), we have $q^{n}=q^{m}$. Applying the expression of $q^{n}$ and $q^{m}$, we obtain

$$
\theta=\alpha\left(1+\frac{1-\gamma}{\gamma} R \pi\right)<1 \Longleftrightarrow \alpha<\alpha_{B C}
$$

(A.2) and $\mu_{1}=0$ imply $u^{\prime}\left(q^{m}\right) \geq 1 \Longleftrightarrow$

$$
1-\left(\frac{\gamma}{\pi}+(1-\gamma) R\right) \frac{d}{q^{*}} \geq \alpha\left\{1-\left(\frac{\gamma}{\pi}+(1-\gamma) R\right) \frac{d}{q^{*}}\right\}
$$


This inequality holds true if and only if

$$
\gamma \geq \frac{\pi R-\frac{\pi q^{*}}{d}}{\pi R-1} \equiv \gamma_{C D}
$$

Region D: $\theta<1$ and $c<\frac{R(1-\gamma) d}{1-\alpha}$. In this case, $\mu_{0}=\mu_{2}=0$. By (A.1), we have $q^{n}=q^{m}$.

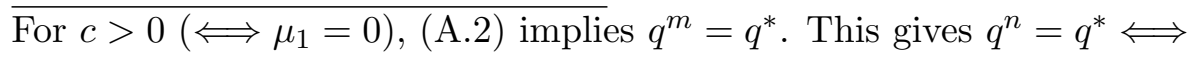

$$
\theta=\frac{\alpha \pi q^{*}}{\gamma d}
$$

Hence, $\theta<1 \Longleftrightarrow \alpha<\alpha_{A D}$. Applying this expression to $q^{m}=q^{*}$, we get

$$
c=\frac{q^{*}-\frac{\gamma d}{\pi}}{1-\alpha} .
$$

We therefore have $c<\frac{R(1-\gamma) d}{1-\alpha} \Longleftrightarrow \gamma<\gamma_{C D}$ and $c>0 \Longleftrightarrow \gamma<\frac{\pi q^{*}}{d} \equiv \gamma_{0}$. For $c=0, \theta=\alpha$ and $q^{n}=q^{m}=\gamma \pi d$. However, (A.2) implies $q^{m} \geq q^{*}$ with strict inequality, which is infeasible, if $\gamma>\gamma_{0}$.

The above covers all the possible cases.

Finally, we check the incentive constraints of buyers. Since $q^{n} \leq q^{m}$, monitored buyers do not have an incentive to misrepresent their type. Remember that a monitored buyer receives $\frac{(1-\theta) \gamma d}{(1-\alpha) \pi}$ money and $c$ capital credit. For a deviating non-monitored buyer who claims to be a monitored buyer, the monetary payment can be used in the DM but the credit is completely useless. Hence, the incentive constraint of non-monitored buyers is

$$
u\left(q^{n}\right) \geq u\left(\frac{(1-\theta) \gamma d}{(1-\alpha) \pi}\right),
$$

where the bank will optimally hold on allocating capital $\frac{k}{1-\alpha}$ if the deviator does not use the allocated claim in the DM. In Region A and B, $\theta=1$ and so (A.3) is satisfied. In Region C, $q^{n}=q^{m}=d\left(\frac{\gamma}{\pi}+R(1-\gamma)\right)$, implying that $q^{n}>\frac{(1-\theta) \gamma d}{(1-\alpha) \pi}$ for any $c \geq 0$. Finally, in Region D, the same argument above can be applied, since $q^{n}=q^{m}=q^{*}$. Hence, we have shown that non-monitored buyers do not have any incentive to misrepresent their types. This completes the proof of Theorem 1.

\section{Proof of Theorem 2}

$\bigodot$ Case $d \leq \pi q^{*}$. For $\gamma \geq \gamma_{C D}$, the bank's problem can be written as

$$
\begin{aligned}
\max _{\gamma \in\left[\gamma_{C D}, 1\right]} \quad \int_{\alpha_{A B}}^{1}\left[\alpha u\left(\frac{\gamma d}{\alpha \pi}\right)+(1-\alpha) u\left(q^{*}\right)-(1-\alpha) q^{*}\right] f(\alpha) d \alpha \\
+\int_{\alpha_{B C}}^{\alpha_{A B}}\left[\alpha u\left(\frac{\gamma d}{\alpha \pi}\right)+(1-\alpha) u\left(\frac{R(1-\gamma) d}{1-\alpha}\right)\right] f(\alpha) d \alpha \\
+\int_{0}^{\alpha_{B C}} u\left(d\left(\frac{\gamma}{\pi}+(1-\gamma) R\right)\right) f(\alpha) d \alpha+\left(1-F\left(\alpha_{A B}\right)\right) R(1-\gamma) d .
\end{aligned}
$$


The first-order condition is given by

$$
\begin{aligned}
\Phi(\gamma, d, \pi) & \equiv \int_{\alpha_{B C}}^{1} \frac{d}{\pi} u^{\prime}\left(\frac{\gamma d}{\alpha \pi}\right) f(\alpha) d \alpha-\int_{\alpha_{B C}}^{\alpha_{A B}} R d u^{\prime}\left(\frac{R(1-\gamma) d}{1-\alpha}\right) f(\alpha) d \alpha \\
& -d\left(R-\frac{1}{\pi}\right) u^{\prime}\left(d\left(\frac{\gamma}{\pi}+R(1-\gamma)\right)\right) F\left(\alpha_{B C}\right)-R d\left(1-F\left(\alpha_{A B}\right)\right)=0 .
\end{aligned}
$$

Observe that $\Phi(1, \cdot)=-d\left(R-\frac{1}{\pi}\right) u^{\prime}\left(\frac{d}{\pi}\right)<0$, and that the second order condition is satisfied:

$$
\begin{gathered}
\frac{\partial \Phi(\gamma, \cdot)}{\partial \gamma}=\int_{\alpha_{B C}}^{1} \frac{d^{2}}{\alpha \pi^{2}} u^{\prime \prime}\left(\frac{\gamma d}{\alpha \pi}\right) f(\alpha) d \alpha+\int_{\alpha_{B C}}^{\alpha_{A B}} \frac{(R d)^{2}}{1-\alpha} u^{\prime \prime}\left(\frac{R(1-\gamma) d}{1-\alpha}\right) f(\alpha) d \alpha \\
+d^{2}\left(R-\frac{1}{\pi}\right)^{2} u^{\prime \prime}\left(d\left(\frac{\gamma}{\pi}+R(1-\gamma)\right)\right) F\left(\alpha_{B C}\right)<0 .
\end{gathered}
$$

Thus, a solution to (A.4) has to be some unique $\gamma(d) \in\left[\gamma_{D C}, 1\right)$ (if it exists).

For $\gamma \leq \min \left\{\gamma_{C D}, \gamma_{0}\right\}=\gamma_{C D}(<1)$, the bank's problem can be written as

$$
\begin{array}{r}
\max _{\gamma \in\left[0, \gamma_{C D}\right]} \int_{\alpha_{A D}}^{1}\left[\alpha u\left(\frac{\gamma d}{\alpha \pi}\right)+(1-\alpha)\left(u\left(q^{*}\right)-q^{*}\right)\right] f(\alpha) d \alpha \\
+\int_{0}^{\alpha_{A D}}\left[u\left(q^{*}\right)-\left(q^{*}-\frac{\gamma d}{\pi}\right)\right] f(\alpha) d \alpha+R(1-\gamma) d .
\end{array}
$$

Differentiating with respect to $\gamma$, yields the first-order condition,

$$
\Psi(\gamma, d, \pi) \equiv \int_{\alpha_{A D}}^{1} \frac{d}{\pi} u^{\prime}\left(\frac{\gamma d}{\alpha \pi}\right) f(\alpha) d \alpha-d\left(R-\frac{F\left(\alpha_{A D}\right)}{\pi}\right)=0 .
$$

Note that $\Psi(0, \cdot)>0$, implying that $\gamma=0$ is never optimal. The second order condition is satisfied,

$$
\frac{\partial \Psi}{\partial \gamma}=\int_{\alpha_{A D}}^{1} \frac{d^{2}}{\alpha \pi^{2}} u^{\prime \prime}\left(q^{n}\right) f(\alpha) d \alpha<0 .
$$

Thus, a solution to (A.5) has to be some unique $\gamma(d) \in\left(0, \gamma_{D C}\right]$ (if it exists).

To combine the above two subcases, observe for $d \leq \frac{q^{*}}{R}$, we have $\gamma_{C D} \equiv \frac{\pi R-\frac{\pi q^{*}}{d}}{\pi R-1} \leq 0$, and so the solution is determined by (A.4). For $d>\frac{q^{*}}{R}$, at $\gamma=\gamma_{C D}>0$ it holds that

$$
\alpha_{A B}=\alpha_{B C}=\alpha_{A D}=\frac{R d-q^{*}}{q^{*}(\pi R-1)} \equiv \hat{\alpha}(d) \in[0,1]
$$

i.e., all the three critical values of $\alpha$ coincide, and therefore that the two objective functions of the bank and their derivatives must coincide. Hence, the bank's objective function is continuous and differentiable at all $\gamma \in[0,1]$, and thereby for $d \leq \pi q^{*}$, there exists a unique solution $\gamma(d) \in(0,1)$ determined either by (A.4) or by (A.5).

Case $d>\pi q^{*}$. In this case, the critical values defined in Theorem 1 satisfy: $\alpha_{A B}<\alpha_{B C}$ and $\gamma_{C D}>\gamma_{0}$. Further, for $\gamma \geq \gamma_{0} \equiv \frac{\pi q^{*}}{d}$, we must have $\alpha_{A D} \geq 1$. Hence, by setting $\gamma(d)=\gamma_{0}$ 
the bank can guarantee that the efficient risk-sharing is achieved, i.e., $q^{n}=q^{m}=q^{*}=\phi_{+} m$ with $c=0$.

$\odot$ The dependence of $\gamma(d)$ on $d$.

Differentiation yields

$$
\begin{aligned}
\frac{\partial \Psi}{\partial d}= & \int_{\alpha_{A D}}^{1} \frac{\gamma d}{\alpha \pi^{2}} u^{\prime \prime}\left(\frac{\gamma d}{\alpha \pi}\right) f(\alpha) d \alpha<0 \\
\frac{\partial \Phi}{\partial d}= & (1-\xi) \int_{\alpha_{B C}}^{1} \frac{d}{\pi} u^{\prime}\left(\frac{\gamma d}{\alpha \pi}\right) f(\alpha) d \alpha-(1-\xi) \int_{\alpha_{B C}}^{\alpha_{A B}} R d u^{\prime}\left(\frac{R(1-\gamma) d}{1-\alpha}\right) f(\alpha) d \alpha \\
& -(1-\xi) d\left(R-\frac{1}{\pi}\right) u^{\prime}\left(d\left(\frac{\gamma}{\pi}+R(1-\gamma)\right)\right) F\left(\alpha_{B C}\right)-R\left(1-F\left(\alpha_{A B}\right)\right) \\
= & -\xi R\left(1-F\left(\alpha_{A B}\right)\right)<0,
\end{aligned}
$$

where $\xi \equiv-\frac{q u^{\prime \prime}(q)}{u^{\prime}(q)}>0$ is a positive constant, and in the last equality, we apply (A.4). Hence, since $\frac{\partial \Psi}{\partial \gamma}, \frac{\partial \Phi}{\partial \gamma}<0$, we have $\frac{\partial \gamma(d)}{\partial d}<0$. This completes the proof of Theorem 2 .

\section{Proof of Proposition 1}

We start by determining which of the conditions, (A.4) or (A.5), should be the one of the optimal $\gamma(d)$ depending on values of $d \leq \pi q^{*}$. Remember from the proof of Theorem 2 , that for $d \leq \frac{q^{*}}{R}$, we have $\gamma_{C D} \equiv \frac{\pi R-\frac{\pi q^{*}}{d}}{\pi R-1} \leq 0$, and so the solution is determined by (A.4). For $d \geq \frac{q^{*}}{R}$, at $\gamma=\gamma_{C D}>0\left(\Longleftrightarrow d \geq \frac{q^{*}}{R}\right)$, all the three critical values of $\alpha$ coincide, taking the value $\hat{\alpha}(d) \equiv \frac{R d-q^{*}}{q^{*}(\pi R-1)} \in[0,1]$, and the conditions (A.5) and (A.4) become $\Psi\left(\gamma_{C D} ; \cdot\right)=$ $\Phi\left(\gamma_{C D} ; \cdot\right)=\frac{d}{\pi} \Upsilon(\hat{\alpha})$ where

$$
\Upsilon(\hat{\alpha}) \equiv \int_{\hat{\alpha}}^{1} u^{\prime}\left(\frac{\hat{\alpha} q^{*}}{\alpha}\right) f(\alpha) d \alpha+F(\hat{\alpha})-R \pi .
$$

Observe that: $\Upsilon(0)=+\infty>0 ; \Upsilon(1)=1-R \pi<0 ; \Upsilon^{\prime}(\cdot)=\int_{\hat{\alpha}}^{1} \frac{q^{*}}{\alpha} u^{\prime \prime}\left(\frac{\hat{\alpha} q^{*}}{\alpha}\right) f(\alpha) d \alpha<0$. Therefore, there exists a $\tilde{d} \in\left(\frac{q^{*}}{R}, \pi q^{*}\right)$ such that $\Upsilon(\hat{\alpha}(\tilde{d}))=0, \Upsilon(\hat{\alpha}(d))>0$ if $d<\tilde{d}, \Upsilon(\hat{\alpha}(d))<$ 0 if $d>\tilde{d}$. Since $\gamma(d)$ is strictly decreasing in $d$, this implies that we must have $\gamma(d)=\gamma_{C D}$ if $d=\tilde{d}, \gamma(d)>\gamma_{C D}$ if $d<\tilde{d}$, and $\gamma(d)<\gamma_{C D}$ if $d>\tilde{d}$.

To summarize the analysis so far,

- for $d \in(0, \tilde{d}], \gamma(d) \in\left[\gamma_{C D}, 1\right)$ is determined by (A.4) and its associated value $\tilde{V}(d \mid \gamma(d))$ is given by (4),

- for $d \in\left(\tilde{d}, \pi q^{*}\right], \gamma(d) \in\left(0, \gamma_{C D}\right)$ is determined by (A.5) and its associated value $\tilde{V}(d)$ $\gamma(d))$ is given by $(5)$,

- for $d \in\left(\pi q^{*}, \infty\right), \gamma(d)=\gamma_{0} \equiv \frac{\pi q^{*}}{d}<1$ and its associated value $\hat{V}(d)$ is given by $(7)$. 
We now compute the derivative of the value function. For $d \in(0, \tilde{d}]$, the differentiation of it in (4) yields

$$
\begin{aligned}
\tilde{V}^{\prime}(d \mid \gamma(d)) & =\int_{\alpha_{B C}}^{1} \frac{\gamma}{\pi} u^{\prime}\left(\frac{\gamma d}{\alpha \pi}\right) f(\alpha) d \alpha+\int_{\alpha_{B C}}^{\alpha_{A B}} R(1-\gamma) u^{\prime}\left(\frac{R(1-\gamma) d}{1-\alpha}\right) f(\alpha) d \alpha \\
& +\left(\frac{\gamma}{\pi}+R(1-\gamma)\right) u^{\prime}\left(d\left(\frac{\gamma}{\pi}+R(1-\gamma)\right)\right) F\left(\alpha_{B C}\right)+R(1-\gamma)\left(1-F\left(\alpha_{A B}\right)\right) \\
& =\frac{1}{\pi}\left[\int_{\alpha_{B C}}^{1} u^{\prime}\left(\frac{\gamma d}{\alpha \pi}\right) f(\alpha) d \alpha+u^{\prime}\left(d\left(\frac{\gamma}{\pi}+R(1-\gamma)\right)\right) F\left(\alpha_{B C}\right)\right]
\end{aligned}
$$

with $\gamma=\gamma(d)$, where the second equality follows from (A.4). It satisfied that $\tilde{V}^{\prime}(d \mid \gamma(d))=R$ if $d=\tilde{d}$. For $d \in\left(\tilde{d}, \pi q^{*}\right]$, the differentiation of it in (5) yields

$$
\tilde{V}^{\prime}(d \mid \gamma(d))=\int_{\alpha_{B C}}^{1} \frac{\gamma}{\pi} u^{\prime}\left(\frac{\gamma d}{\alpha \pi}\right) f(\alpha) d \alpha+\frac{\gamma}{\pi} F\left(\alpha_{A D}\right)+R(1-\gamma)=R
$$

with $\gamma=\gamma(d)$, where the second equality follows from (A.5). For $d>\pi q^{*}$, (7) implies

$$
\hat{V}^{\prime}(d)=R
$$

We now derive the monetary equilibrium with bank deposit. The equilibrium deposit $d>0$ has to satisfy the optimality condition,

$$
1=\beta V^{\prime}(d)
$$

If $\beta R<1$, we must have $V^{\prime}(d)>R$. The only possibility is $d<\tilde{d}$. Using (A.6), we can write the fixed point condition of the equilibrium as

$$
\frac{\pi}{\beta}=\int_{\alpha_{B C}}^{1} u^{\prime}\left(\frac{\gamma d}{\alpha \pi}\right) f(\alpha) d \alpha+u^{\prime}\left(d\left(\frac{\gamma}{\pi}+R(1-\gamma)\right)\right) F\left(\alpha_{B C}\right) \equiv \Omega(d),
$$

with $\gamma=\gamma(d)$. Observe that: $\Omega(0)=+\infty>\frac{\pi}{\beta} ; \Omega(\tilde{d})=\int_{\hat{\alpha}}^{1} u^{\prime}\left(\frac{\hat{\alpha} q^{*}}{\alpha}\right) f(\alpha) d \alpha+F(\hat{\alpha})=\pi R<\frac{\pi}{\beta}$ (the second equality follows from (A.4));

$$
\begin{aligned}
\Omega^{\prime}(d)= & \int_{\alpha_{B C}}^{1} \frac{\gamma}{\alpha \pi} u^{\prime \prime}\left(\frac{\gamma d}{\alpha \pi}\right) f(\alpha) d \alpha+\left(\frac{\gamma}{\pi}+R(1-\gamma)\right) u^{\prime \prime}\left(d\left(\frac{\gamma}{\pi}+R(1-\gamma)\right)\right) F\left(\alpha_{B C}\right) \\
& +\frac{\partial \gamma}{\partial d}\left[\int_{\alpha_{B C}}^{1} \frac{d}{\alpha \pi} u^{\prime \prime}\left(\frac{\gamma d}{\alpha \pi}\right) f(\alpha) d \alpha-d\left(R-\frac{1}{\pi}\right) u^{\prime \prime}\left(d\left(\frac{\gamma}{\pi}+R(1-\gamma)\right)\right) F\left(\alpha_{B C}\right)\right] .
\end{aligned}
$$

Since $\frac{\partial \gamma}{\partial d}<0$, if it holds that

$$
\gamma+d \frac{\partial \gamma}{\partial d}>0
$$

then $\Omega^{\prime}(d)<0$. This can be shown by the following steps. First, we can arrange it to $(\mathrm{A} .8) \Longleftrightarrow \frac{\frac{\partial \Phi}{\partial d}}{\frac{\partial \Phi}{\partial \gamma}}<\frac{\gamma}{d} \Longleftrightarrow \xi R\left(1-F\left(\alpha_{A B}\right)\right)<-\frac{\gamma}{d} \frac{\partial \Phi}{\partial \gamma}$ (see the proof of Theorem 2 for these 
derivative expressions). Second, using the expression $\xi \equiv-\frac{q u^{\prime \prime}(q)}{u^{\prime}(q)}$, we can write

$$
\begin{aligned}
\frac{\partial \Phi}{\partial \gamma}= & \int_{\alpha_{B C}}^{1} \frac{d^{2}}{\alpha \pi^{2}} u^{\prime \prime}\left(\frac{\gamma d}{\alpha \pi}\right) f(\alpha) d \alpha+\int_{\alpha_{B C}}^{\alpha_{A B}} \frac{(R d)^{2}}{1-\alpha} u^{\prime \prime}\left(\frac{R(1-\gamma) d}{1-\alpha}\right) f(\alpha) d \alpha \\
& +d^{2}\left(R-\frac{1}{\pi}\right)^{2} u^{\prime \prime}\left(d\left(\frac{\gamma}{\pi}+R(1-\gamma)\right)\right) F\left(\alpha_{B C}\right) \\
= & -\xi\left[\int_{\alpha_{B C}}^{1} \frac{d}{\pi \gamma} u^{\prime}\left(\frac{\gamma d}{\alpha \pi}\right) f(\alpha) d \alpha+\int_{\alpha_{B C}}^{\alpha_{A B}} \frac{R d}{1-\gamma} u^{\prime}\left(\frac{R(1-\gamma) d}{1-\alpha}\right) f(\alpha) d \alpha\right. \\
& \left.+\frac{d\left(R-\frac{1}{\pi}\right)^{2}}{\frac{\gamma}{\pi}+R(1-\gamma)} u^{\prime}\left(d\left(\frac{\gamma}{\pi}+R(1-\gamma)\right)\right) F\left(\alpha_{B C}\right)\right] .
\end{aligned}
$$

Finally, using the last expression, we have

$$
\begin{array}{r}
\pi R\left(1-F\left(\alpha_{A B}\right)\right)<\int_{\alpha_{B C}}^{1} u^{\prime}\left(\frac{\gamma d}{\alpha \pi}\right) f(\alpha) d \alpha+\int_{\alpha_{B C}}^{\alpha_{A B}} \frac{\pi R \gamma}{1-\gamma} u^{\prime}\left(\frac{R(1-\gamma) d}{1-\alpha}\right) f(\alpha) d \alpha \\
+\frac{\pi \gamma\left(R-\frac{1}{\pi}\right)^{2}}{\frac{\gamma}{\pi}+R(1-\gamma)} u^{\prime}\left(d\left(\frac{\gamma}{\pi}+R(1-\gamma)\right)\right) F\left(\alpha_{B C}\right) \\
\Longleftrightarrow \quad-\int_{\alpha_{B C}}^{\alpha_{A B}} \frac{\pi R}{1-\gamma} u^{\prime}\left(\frac{R(1-\gamma) d}{1-\alpha}\right) f(\alpha) d \alpha<\frac{R\left(R-\frac{1}{\pi}\right)}{\frac{\gamma}{\pi}+R(1-\gamma)} u^{\prime}\left(d\left(\frac{\gamma}{\pi}+R(1-\gamma)\right)\right) F\left(\alpha_{B C}\right),
\end{array}
$$

which is true (we use (A.4) to reach the last expression). We therefore have shown that there exists a unique $d \in(0, \tilde{d})$ such that the fixed point condition (A.7) is satisfied. Given this solution, $\gamma(d) \in\left(\gamma_{C D}, 1\right)$ is determined by (A.4), and $\left(q^{n}, q^{m}\right) \leq q^{*}$ is determined as described in Theorem 1 (Region A, B or C). This satisfies all the equilibrium conditions and so describes a monetary equilibrium with bank deposit.

If $\beta R=1$, we must have $V^{\prime}(d)=R$, which is the case if and only if $d \geq \tilde{d}$. Hence, a monetary equilibrium with bank deposit exists but is indeterminate with any $d \in[\tilde{d}, \infty)$. In equilibria with $d \in\left[\tilde{d}, \pi q^{*}\right]$, we have $\gamma(d) \in\left(0, \gamma_{C D}\right]$ determined by (A.5) and $\left(q^{n}, q^{m}\right) \leq q^{*}$ in Region A or D, while in equilibria with $d>\pi q^{*}$, we have $\gamma(d)=\gamma_{0}$ and $q^{n}=q^{m}=q^{*}$ in Region D. This completes the proof of Proposition 1.

\section{Proof of Proposition 2}

In what follows, keep in mind that with $\beta R<1$, the equilibrium $\gamma(d) \in\left(\gamma_{C D}, 1\right)$ and $d \in(0, \tilde{d})$, with $\tilde{d} \in\left(\frac{\pi}{R}, \pi q^{*}\right)$, are jointly determined by (A.4) and (A.7).

$\bigodot$ The limit as $\pi \rightarrow \frac{1}{R}>\beta$. For any value of $\gamma=\gamma(d)$, we must have

$$
\alpha_{B C} \equiv \frac{\gamma}{\gamma+(1-\gamma) \pi R} \rightarrow 1 \text { as } \pi \rightarrow \frac{1}{R}
$$

Also, we see that

$$
\alpha_{A B} \equiv 1-\frac{R(1-\gamma) d}{q^{*}} \rightarrow 1 \text { as } \pi \rightarrow \frac{1}{R}
$$


is the only solution to (A.4), which implies

$$
\gamma=\gamma(d) \rightarrow 1 \text { as } \pi \rightarrow \frac{1}{R}
$$

Finally, given all these limiting values, (A.7) becomes

$$
\frac{1}{\beta R}=u^{\prime}(d R) \text { as } \pi \rightarrow \frac{1}{R},
$$

which holds true if and only if

$$
d<\frac{q^{*}}{R} \text { as } \pi \rightarrow \frac{1}{R}
$$

$\bigodot$ The limit as $\pi \rightarrow \frac{1}{R}$ and $\pi \rightarrow \beta$. The outcome is the same as above with $\pi \rightarrow \frac{1}{R}>\beta$, except that by (A.9),

$$
d \rightarrow \pi q^{*} \text { as } \pi \rightarrow \frac{1}{R} \text { and } \pi \rightarrow \beta
$$

Combining the above two limiting results proves the claim. This completes the proof of Proposition 2.

\section{Proof of Proposition 3}

Remember that given $d$ and $\pi$, (A.5) determines $\gamma=\gamma(d, \pi) \in\left(\gamma_{C D}, 1\right)$ satisfying

$$
\Phi(\gamma, d, \pi)=0 .
$$

To reflect the dependence of the equilibrium on $\pi$, the fixed-point condition (A.7) shall be written as

$$
\Theta(\gamma, d, \pi) \equiv \Omega(\gamma, d, \pi)-\frac{\pi}{\beta}=0 .
$$

These implicit equations determine two continuous and differentiable function $d=d(\pi)$ and $\gamma=\gamma(\pi)$ which are characterized as follows:

$$
\begin{aligned}
\left(\begin{array}{c}
\frac{\partial \gamma(\pi)}{\partial \pi} \\
\frac{\partial d(\pi)}{\partial \pi}
\end{array}\right) & =-\left(\begin{array}{cc}
\frac{\partial \Phi}{\partial \gamma} & \frac{\partial \Phi}{\partial d} \\
\frac{\partial \Theta}{\partial \gamma} & \frac{\partial \Theta}{\partial d}
\end{array}\right)^{-1}\left(\begin{array}{c}
\frac{\partial \Phi}{\partial \pi} \\
\frac{\partial \Theta}{\partial \pi}
\end{array}\right) \\
& =-\frac{1}{\Lambda}\left(\begin{array}{cc}
\frac{\partial \Theta}{\partial d} & -\frac{\partial \Phi}{\partial d} \\
-\frac{\partial \Theta}{\partial \gamma} & \frac{\partial \Phi}{\partial \gamma}
\end{array}\right)\left(\begin{array}{c}
\frac{\partial \Phi}{\partial \pi} \\
\frac{\partial \Theta}{\partial \pi}
\end{array}\right)
\end{aligned}
$$

where

$$
\Lambda \equiv \operatorname{det}\left(\begin{array}{ll}
\frac{\partial \Phi}{\partial \gamma} & \frac{\partial \Phi}{\partial d} \\
\frac{\partial \Theta}{\partial \gamma} & \frac{\partial \Theta}{\partial d}
\end{array}\right)=\frac{\partial \Phi}{\partial \gamma} \frac{\partial \Theta}{\partial d}-\frac{\partial \Phi}{\partial d} \frac{\partial \Theta}{\partial \gamma}=\frac{\partial \Phi}{\partial \gamma}\left(\frac{\partial \Theta}{\partial d}+\frac{\partial \gamma}{\partial d} \frac{\partial \Theta}{\partial \gamma}\right)>0
$$


since $\frac{\partial \Phi}{\partial \gamma}<0$ (see the proof of Theorem 2) and $\frac{\partial \Theta}{\partial d}+\frac{\partial \gamma}{\partial d} \frac{\partial \Theta}{\partial \gamma}=\Omega^{\prime}(\cdot)<0$ (see the proof of Proposition 1).

$\bigodot$ The effect on $\gamma(\pi)$ and $1-F\left(\alpha_{B C}\right)$. Now, from (A.10), we get

$$
\Lambda \frac{\partial \gamma(\pi)}{\partial \pi}=-\frac{\partial \Theta}{\partial d} \frac{\partial \Phi}{\partial \pi}+\frac{\partial \Phi}{\partial d} \frac{\partial \Theta}{\partial \pi} .
$$

Partial differentiation in (A.7) yields

$$
\begin{aligned}
\frac{\partial \Theta}{\partial d} & =\int_{\alpha_{B C}}^{1} \frac{\gamma}{\alpha \pi} u^{\prime \prime}\left(\frac{\gamma d}{\alpha \pi}\right) f(\alpha) d \alpha+\left(\frac{\gamma}{\pi}+R(1-\gamma)\right) u^{\prime \prime}\left(d\left(\frac{\gamma}{\pi}+R(1-\gamma)\right)\right) F\left(\alpha_{B C}\right) \\
& =-\frac{\xi}{d}\left[\int_{\alpha_{B C}}^{1} u^{\prime}\left(\frac{\gamma d}{\alpha \pi}\right) f(\alpha) d \alpha+u^{\prime}\left(d\left(\frac{\gamma}{\pi}+R(1-\gamma)\right)\right) F\left(\alpha_{B C}\right)\right] \\
& =-\frac{\xi}{d} \frac{\pi}{\beta},
\end{aligned}
$$

where we apply $\xi \equiv-\frac{u^{\prime \prime}(q) q}{u^{\prime}(q)}$ in the second equality, and (A.7) in the third equality. Similarly,

$$
\begin{aligned}
\frac{\partial \Theta}{\partial \pi} & =-\int_{\alpha_{B C}}^{1} \frac{\gamma d}{\alpha \pi^{2}} u^{\prime \prime}\left(\frac{\gamma d}{\alpha \pi}\right) f(\alpha) d \alpha-\frac{d \gamma}{\pi^{2}} u^{\prime \prime}\left(d\left(\frac{\gamma}{\pi}+R(1-\gamma)\right)\right) F\left(\alpha_{B C}\right)-\frac{1}{\beta} \\
& =\frac{\xi}{\pi}\left[\int_{\alpha_{B C}}^{1} u^{\prime}\left(\frac{\gamma d}{\alpha \pi}\right) f(\alpha) d \alpha+\frac{\gamma}{\gamma+(1-\gamma) \pi R} u^{\prime}\left(d\left(\frac{\gamma}{\pi}+R(1-\gamma)\right)\right) F\left(\alpha_{B C}\right)\right]-\frac{1}{\beta} \\
& =-\frac{1-\xi}{\beta}-\frac{\xi(1-\gamma) R}{\gamma+(1-\gamma) \pi R} u^{\prime}\left(d\left(\frac{\gamma}{\pi}+R(1-\gamma)\right)\right) F\left(\alpha_{B C}\right) .
\end{aligned}
$$

We know from the proof of Theorem 2 that $\frac{\partial \Phi}{\partial d}=-\xi R\left(1-F\left(\alpha_{A B}\right)\right)$. In addition,

$$
\begin{aligned}
\frac{\partial \Phi}{\partial \pi} & =-\int_{\alpha_{B C}}^{1} \frac{d(1-\xi)}{\pi^{2}} u^{\prime}\left(\frac{\gamma d}{\alpha \pi}\right) f(\alpha) d \alpha-\frac{d}{\pi}\left(\frac{\xi \gamma\left(R-\frac{1}{\pi}\right)}{\gamma+(1-\gamma) \pi R}+\frac{1}{\pi}\right) u^{\prime}\left(d\left(\frac{\gamma}{\pi}+R(1-\gamma)\right)\right) F\left(\alpha_{B C}\right) \\
& =-\frac{d(1-\xi)}{\pi \beta}-\frac{d}{\pi} \frac{\xi R}{\gamma+(1-\gamma) \pi R} u^{\prime}\left(d\left(\frac{\gamma}{\pi}+R(1-\gamma)\right)\right) F\left(\alpha_{B C}\right) .
\end{aligned}
$$

Applying these expression to (A.11), we get

$$
\begin{aligned}
\Lambda \frac{\partial \gamma(\pi)}{\partial \pi}= & -\frac{\partial \Theta}{\partial d} \frac{\partial \Phi}{\partial \pi}+\frac{\partial \Phi}{\partial d} \frac{\partial \Theta}{\partial \pi} \\
= & -\frac{\xi(1-\xi)}{\beta}\left(\frac{1}{\beta}-R\left(1-F\left(\alpha_{A B}\right)\right)\right) \\
& -\frac{\xi^{2} R}{\gamma+(1-\gamma) \pi R}\left(\frac{1}{\beta}-R\left(1-F\left(\alpha_{A B}\right)\right)(1-\gamma)\right) u^{\prime}\left(d\left(\frac{\gamma}{\pi}+R(1-\gamma)\right)\right) F\left(\alpha_{B C}\right)<0
\end{aligned}
$$

for all $\xi \in(0,1)$. This proves Claim 1 . This also proves Claim 2 because this leads to the decreasing critical value of banking panics $\alpha_{B C}=\frac{\gamma}{\gamma+(1-\gamma) \pi R}$, and the increasing probability of banking panics, $1-F\left(\alpha_{B C}\right)$.

$\bigodot$ The effect on $d(\pi)$. Now, from (A.10), we get

$$
\Lambda \frac{\partial d(\pi)}{\partial \pi}=\frac{\partial \Theta}{\partial \gamma} \frac{\partial \Phi}{\partial \pi}-\frac{\partial \Phi}{\partial \gamma} \frac{\partial \Theta}{\partial \pi} .
$$


Partial differentiation in (A.7) yields

$$
\begin{aligned}
\frac{\partial \Theta}{\partial \gamma} & =\int_{\alpha_{B C}}^{1} \frac{d}{\alpha \pi} u^{\prime \prime}\left(\frac{\gamma d}{\alpha \pi}\right) f(\alpha) d \alpha-d\left(R-\frac{1}{\pi}\right) u^{\prime \prime}\left(d\left(\frac{\gamma}{\pi}+R(1-\gamma)\right)\right) F\left(\alpha_{B C}\right) \\
& =-\frac{\xi}{\gamma}\left[\int_{\alpha_{B C}}^{1} u^{\prime}\left(\frac{\gamma d}{\alpha \pi}\right) f(\alpha) d \alpha-\frac{(R \pi-1) \gamma}{\gamma+(1-\gamma) \pi R} u^{\prime}\left(d\left(\frac{\gamma}{\pi}+R(1-\gamma)\right)\right) F\left(\alpha_{B C}\right)\right] \\
& =-\frac{\xi}{\gamma}\left[\frac{\pi}{\beta}-\frac{\pi R}{\gamma+(1-\gamma) \pi R} u^{\prime}\left(d\left(\frac{\gamma}{\pi}+R(1-\gamma)\right)\right) F\left(\alpha_{B C}\right)\right] .
\end{aligned}
$$

The derivative expression derived in the proof of Proposition 1 can be rearranged to

$$
\begin{aligned}
\frac{\partial \Phi}{\partial \gamma}= & -\xi\left[\int_{\alpha_{B C}}^{1} \frac{d}{\pi \gamma} u^{\prime}\left(\frac{\gamma d}{\alpha \pi}\right) f(\alpha) d \alpha+\int_{\alpha_{B C}}^{\alpha_{A B}} \frac{R d}{1-\gamma} u^{\prime}\left(\frac{R(1-\gamma) d}{1-\alpha}\right) f(\alpha) d \alpha\right. \\
& \left.+\frac{d\left(R-\frac{1}{\pi}\right)^{2}}{\frac{\gamma}{\pi}+R(1-\gamma)} u^{\prime}\left(d\left(\frac{\gamma}{\pi}+R(1-\gamma)\right)\right) F\left(\alpha_{B C}\right)\right] \\
= & -\frac{\xi d}{1-\gamma}\left[\int_{\alpha_{B C}}^{1} \frac{1}{\pi \gamma} u^{\prime}\left(\frac{\gamma d}{\alpha \pi}\right) f(\alpha) d \alpha\right. \\
& \left.-\frac{R-\frac{1}{\pi}}{\gamma+(1-\gamma) \pi R} u^{\prime}\left(d\left(\frac{\gamma}{\pi}+R(1-\gamma)\right)\right) F\left(\alpha_{B C}\right)-R\left(1-F\left(\alpha_{A B}\right)\right)\right] \\
= & -\frac{\xi d}{\gamma(1-\gamma)}\left[\frac{1}{\beta}-\frac{R}{\gamma+(1-\gamma) \pi R} u^{\prime}\left(d\left(\frac{\gamma}{\pi}+R(1-\gamma)\right)\right) F\left(\alpha_{B C}\right)-R \gamma\left(1-F\left(\alpha_{A B}\right)\right)\right],
\end{aligned}
$$

where we use (A.4) in the second equality and (A.7) in the third equality. Applying these derivative expressions, we obtain:

$$
\begin{aligned}
& \gamma(d \xi)^{-1} \Lambda \frac{\partial d(\pi)}{\partial \pi} \\
= & {\left[\frac{1}{\beta}-\frac{R u^{\prime}\left(d\left(\frac{\gamma}{\pi}+R(1-\gamma)\right)\right) F\left(\alpha_{B C}\right)}{\gamma+(1-\gamma) \pi R}\right]\left[\frac{1-\xi}{\beta}+\frac{\xi R u^{\prime}\left(d\left(\frac{\gamma}{\pi}+R(1-\gamma)\right)\right) F\left(\alpha_{B C}\right)}{\gamma+(1-\gamma) \pi R}\right] } \\
& -\left[\frac{1}{\beta}-\frac{R u^{\prime}\left(d\left(\frac{\gamma}{\pi}+R(1-\gamma)\right)\right) F\left(\alpha_{B C}\right)}{\gamma+(1-\gamma) \pi R}-R \gamma\left(1-F\left(\alpha_{A B}\right)\right)\right]\left[\frac{1-\xi}{\beta(1-\gamma)}+\frac{\xi R u^{\prime}\left(d\left(\frac{\gamma}{\pi}+R(1-\gamma)\right)\right) F\left(\alpha_{B C}\right)}{\gamma+(1-\gamma) \pi R}\right] .
\end{aligned}
$$

Observe that this equation is linear in $\xi$. As $\xi \rightarrow 1$, it approaches to

$$
R \gamma\left(1-F\left(\alpha_{A B}\right)\right) \frac{R u^{\prime}\left(d\left(\frac{\gamma}{\pi}+R(1-\gamma)\right)\right) F\left(\alpha_{B C}\right)}{\gamma+(1-\gamma) \pi R}>0,
$$

while as $\xi \rightarrow 0$, it approaches to

$$
-\left[\frac{1}{\beta}-\frac{R u^{\prime}\left(d\left(\frac{\gamma}{\pi}+R(1-\gamma)\right)\right) F\left(\alpha_{B C}\right)}{\gamma+(1-\gamma) \pi R}-R\left(1-F\left(\alpha_{A B}\right)\right)\right] \frac{\gamma}{\beta(1-\gamma)}<0,
$$

because

$$
\begin{aligned}
1-\frac{R \beta u^{\prime}\left(d\left(\frac{\gamma}{\pi}+R(1-\gamma)\right)\right) F\left(\alpha_{B C}\right)}{\gamma+(1-\gamma) \pi R}-R \beta\left(1-F\left(\alpha_{A B}\right)\right) & >F\left(\alpha_{A B}\right)-F\left(\alpha_{B C}\right) \frac{u^{\prime}\left(d\left(\frac{\gamma}{\pi}+R(1-\gamma)\right)\right)}{\gamma+(1-\gamma) \pi R} \\
& >F\left(\alpha_{A B}\right)-F\left(\alpha_{B C}\right)>0,
\end{aligned}
$$


where the last inequality follows from $u^{\prime}(q) \rightarrow u^{\prime}\left(q^{*}\right)=1$ for any $q \in\left(0, q^{*}\right)$ as $\xi \rightarrow 0$. Hence, there exists a unique cutoff value $\hat{\xi} \in(0,1)$ such that $\frac{\partial d(\pi)}{\partial \pi}<0$ for $\xi<\hat{\xi}$ and $\frac{\partial d(\pi)}{\partial \pi}>0$ for $\xi>\hat{\xi}$. This proves Claim 3 .

$\bigodot$ The effect on $k=d(1-\gamma)$. Observe that:

$$
\frac{\partial k}{\partial \pi}=\frac{\partial d}{\partial \pi}(1-\gamma)-d \frac{\partial \gamma}{\partial \pi}
$$

Hence, since $\frac{\partial \gamma}{\partial \pi}<0$, when $\xi$ is high so that $\frac{\partial d}{\partial \pi}>0$, we have $\frac{\partial k}{\partial \pi}>0$. When $\xi$ is low so that $\frac{\partial d}{\partial \pi}<0$, the final effect depends on the rate of inflation $\pi$. When $\pi$ is low (around the limit $\pi \rightarrow \frac{1}{R}$ ), we have $\gamma \rightarrow 1$ (which implies $k \rightarrow 0$ ) and so $\frac{\partial k}{\partial \pi}>0$.

To investigate the effect for high inflation, observe that as $\pi \rightarrow \infty$,

$$
\alpha_{B C} \equiv \frac{\gamma}{\gamma+(1-\gamma) \pi R} \rightarrow 0 \text { as } \pi \rightarrow \infty
$$

Also, we see that $\gamma \rightarrow 0$ and/or $d \rightarrow 0$ is the only possible solution to (A.4) and (A.7). If $d \rightarrow 0$ (which implies $k \rightarrow 0$ ) as $\pi \rightarrow \infty$, then we must have $\frac{\partial k}{\partial \pi}<0$ as $\pi \rightarrow \infty$. If $d>0$ (which implies $k \rightarrow 0$ ) as $\pi \rightarrow \infty$, then we must have $\gamma \rightarrow 0$. Since $\frac{\gamma}{d} \rightarrow 0$ as $\pi \rightarrow \infty$, observe that

$$
\left|\gamma(d \xi)^{-1} \Lambda \frac{\partial \gamma(\pi)}{\partial \pi}\right| \rightarrow 0
$$

while

$$
\left|\gamma(d \xi)^{-1} \Lambda \frac{\partial d(\pi)}{\partial \pi}\right| \neq 0
$$

as $\pi \rightarrow \infty$. Hence,

$$
\operatorname{sign}\left[\frac{\partial k}{\partial \pi}\right] \rightarrow \operatorname{sign}\left[\frac{\partial d}{\partial \pi}(1-\gamma)\right]=\text { negative }
$$

as $\pi \rightarrow \infty$. Hence, this proves Claim 4 .

$\bigodot$ The effect on $\phi m=d \gamma$. We follow similar steps to the above. Observe that:

$$
\frac{\partial \phi m}{\partial \pi}=\frac{\partial d}{\partial \pi} \gamma+d \frac{\partial \gamma}{\partial \pi}
$$

Hence, since $\frac{\partial \gamma}{\partial \pi}<0$, when $\xi$ is low so that $\frac{\partial d}{\partial \pi}<0$, we have $\frac{\partial k}{\partial \pi}<0$. When $\xi$ is high so that $\frac{\partial d}{\partial \pi}>0$, the final effect depends on the rate of inflation $\pi$.

When $\pi$ is low (around the limit $\pi \rightarrow \frac{1}{R}$ ), we have $\gamma \rightarrow 1$ and so

$$
\left|\gamma(d \xi)^{-1} \Lambda \frac{\partial d(\pi)}{\partial \pi}\right| \rightarrow \infty>\left|\gamma(d \xi)^{-1} \Lambda \frac{\partial \gamma(\pi)}{\partial \pi}\right|
$$


Hence,

$$
\operatorname{sign}\left[\frac{\partial \phi m}{\partial \pi}\right] \rightarrow \operatorname{sign}\left[\frac{\partial d}{\partial \pi} \gamma\right]=\text { positive }
$$

as $\pi \rightarrow \frac{1}{R}$. When $\pi$ is high, we see that $\gamma \rightarrow 0$ and/or $d \rightarrow 0$ is the only possible solution to (A.4) and (A.7) as $\pi \rightarrow \infty$. In any case, $\phi m=d \gamma \rightarrow 0$ as $\pi \rightarrow \infty$ and so we must have $\frac{\partial \phi m}{\partial \pi}<0$ as $\pi \rightarrow \infty$. This proves Claim 5 .

This completes the proof of Proposition 3. 


\section{References}

[1] Ahmed, S., and Rogers, J. H. (2000). Inflation and the great ratios: Long term evidence from the US. Journal of Monetary Economics, 45(1), 3-35.

[2] Andolfatto, D., Berentsen, A., and Martin, F. M. (2017). Money, banking and financial markets. Federal Reserve Bank of St. Louis Working Paper Series, (2017-023).

[3] Andolfatto, D., and Nosal, E., (2008). Bank incentives, contract design, and bank runs. Journal of Economic Theory, 142, 28-47.

[4] Andolfatto, D., Nosal, E., and Wallace, N. (2007). The role of independence in the GreenLin Diamond-Dybvig model. Journal of Economic Theory, 137, 709-715.

[5] Antinolfi, G., Huybens, E., and Keister, T. (2001). Monetary stability and liquidity crises: The role of the lender of last resort. Journal of Economic Theory, 99(1-2), 187-219.

[6] Antinolfi, G., and Keister, T. (2006). Discount window policy, banking crises, and indeterminacy of equilibrium. Macroeconomic Dynamics, 10(01), 1-19.

[7] Allen, F. and Gale, D. (1998). Optimal financial crises. Journal of Finance, 53(4), 12451284.

[8] Allen, F. and Gale, D. (2004). Financial intermediaries and markets. Econometrica, 72(4), 1023-1061.

[9] Allen, F., Carletti, E., and Gale, D. (2014). Money, financial stability and efficiency. Journal of Economic Theory, 149, 100-127.

[10] Bencivenga, V. R., and Camera, G. (2011). Banking in a matching model of money and capital. Journal of Money, Credit and Banking, 43(s2), 449-476.

[11] Berentsen, A., Camera, G., and Waller, C. (2007). Money, credit and banking. Journal of Economic Theory, 135(1), 171-195.

[12] Boyd, J. H., Levine, R., and Smith, B. D. (2001). The impact of inflation on financial sector performance. Journal of Monetary Economics, 47(2), 221-248. 
[13] Boyd, J. H., De Nicolo, G., and Smith, B. D. (2004). Crises in competitive versus monopolistic banking systems. Journal of Money, Credit and Banking, 487-506.

[14] Boyd, J. H., Gomis-Porqueras, P., Kwak, S., and Smith, B. D. (2014). A User's Guide to Banking Crises. Annals of Economics and Finance, 15(2), 800-892.

[15] Bruno, M., and Easterly, W. (1998). Inflation crises and long-run growth. Journal of Monetary Economics, 41(1), 3-26.

[16] Bullard, J., and Keating, J. W. (1995). The long-run relationship between inflation and output in postwar economies. Journal of Monetary Economics, 36(3), 477-496.

[17] Calomiris, C. W., and Gorton, G. (1991). The origins of banking panics: models, facts, and bank regulation. In Financial markets and financial crises (pp. 109-174). University of Chicago Press.

[18] Champ, B., Smith, B. D., and Williamson, S. D. (1996). Currency elasticity and banking panics: Theory and evidence. Canadian Journal of Economics, 828-864.

[19] Chang, R., and Velasco, A. (2000). Financial fragility and the exchange rate regime. Journal of Eeconomic Theory, 92(1), 1-34.

[20] Chari, V. V. (1989). Banking without deposit insurance or bank panics: Lessons from a model of the US National Banking System. Federal Reserve Bank of Minneapolis Quarterly Review, 13(3), 3-19.

[21] Crosby, M., and Otto, G. (2000). Inflation and the capital stock. Journal of Money, Credit and Banking, 236-253.

[22] Davis, E. P., Karim, D., and Liadze, I. (2011). Should multivariate early warning systems for banking crises pool across regions? Review of World Economics, 147(4), 693-716.

[23] Demirguc-Kunt, A., and Detragiache, E. (1998). The determinants of banking crises in developing and developed countries. Staff Papers, 45(1), 81-109.

[24] Demirguc-Kunt, A., and Detragiache, E. (2005). Cross-country empirical studies of systemic bank distress: a survey. National Institute Economic Review, 192(1), 68-83. 
[25] Diamond, D. W., and Dybvig, P. H. (1983). Bank runs, deposit insurance, and liquidity. Journal of Political Economy, 91(3), 401-419.

[26] Diamond, D. W., and Rajan, R. G. (2006). Money in a theory of banking. American Economic Review, 96(1), 30-53.

[27] Duttagupta, R., and Cashin, P. (2011). Anatomy of banking crises in developing and emerging market countries. Journal of International Money and Finance, 30(2), 354-376.

[28] Ennis, H. M., and Keister, T. (2006). Bank runs and investment decisions revisited. Journal of Monetary Economics, 53(2), 217-232.

[29] Ennis, H. M., and Keister, T. (2009). Bank runs and institutions: The perils of intervention. American Economic Review, 99(4), 1588-1607.

[30] Ennis, H. M., and Keister, T. (2010). Banking panics and policy responses. Journal of Monetary Economics, 57(4), 404-419.

[31] Ferraris, L., and Watanabe, M. (2008). Collateral secured loans in a monetary economy. Journal of Economic Theory, 143(1), 405-424.

[32] Ferraris, L., and Watanabe, M. (2011). Collateral fluctuations in a monetary economy. Journal of Economic Theory, 146(5), 1915-1940.

[33] Ferraris, L., and Watanabe, M. (2012). Liquidity constraints in a monetary economy. International Economic Review, 53, 255-277.

[34] Gertler, M., and Kiyotaki, N. (2015). Banking, liquidity, and bank runs in an infinite horizon economy. American Economic Review, 105(7), 2011-2043.

[35] Gomis-Porqueras, P., and Smith, B. D. (2003). Seasonality and monetary policy. Macroeconomic Dynamics, 7(04), 477-502.

[36] Gomis-Porqueras, P., and Smith, B. (2006). The seasonality of banking failures during the late National Banking Era. Canadian Journal of Economics/Revue canadienne d'economique, 39(1), 296-319. 
[37] Green, E.J. and Lin, O. (2003), Implementing efficient allocations in a model of financial intermediation. Journal of Economic Theory 109, 1-23.

[38] Gu, C., Mattesini, F., Monnet, C., and Wright, R. (2012). Banking: A new monetarist approach. The Review of Economic Studies, 80, 636E62.

[39] Hardy, D. C., and Pazarbasioglu, C. (1999). Determinants and leading indicators of banking crises: Further evidence. IMF Economic Review, 46(3), 247-258.

[40] Hua Jiang, J. (2008). Banking crises in monetary economies. Canadian Journal of Economics/Revue canadienne d'economique, 41(1), 80-104.

[41] Joyce, J. P. (2011). Financial globalization and banking crises in emerging markets. Open Economies Review, 22(5), 875-895.

[42] King, R. G., and Watson, M. W. (1997). Testing long-run neutrality. Economic QuarterlyFederal Reserve Bank of Richmond, 83(3), 69.

[43] Kiyotaki, N., and Wright, R. (1989). On money as a medium of exchange. Journal of Political Economy, 97(4), 927-954.

[44] Kiyotaki, N., and Wright, R. (1991). A contribution to the pure theory of money. Journal of Economic Theory, 53(2), 215-235.

[45] Khan, M. S., and Senhadji, A. S. (2001). Threshold effects in the relationship between inflation and growth. IMF Staff papers, 48(1), 1-21.

[46] Khan, M. S., Senhadji, A. S., and Smith, B. D. (2006). Inflation and financial depth. Macroeconomic Dynamics, 10(2), 165-182.

[47] Kremer, S., Bick, A., and Nautz, D. (2013). Inflation and growth: new evidence from a dynamic panel threshold analysis. Empirical Economics, 1-18.

[48] Lagos, R., and Wright, R. (2005). A unified framework for monetary theory and policy analysis. Journal of Political Economy, 113(3), 463-484. 
[49] Matsuoka, T. (2012). Imperfect interbank markets and the lender of last resort. Journal of Economic Dynamics and Control, 36(11), 1673-1687.

[50] Miron, J. A. (1986). Financial panics, the seasonality of the nominal interest rate, and the founding of the Fed. American Economic Review, 76(1), 125-140.

[51] Peck, J., and Shell, K. (2003). Equilibrium bank runs. Journal of Political Economy, 111(1), 103-123.

[52] Skeie, D. R. (2008). Banking with nominal deposits and inside money. Journal of Financial Intermediation, 17(4), 562-584.

[53] Smith, B. D. (2002). Monetary policy, banking crises, and the Friedman rule. American Economic Review, 92(2), 128-134.

[54] Smith, B. D. (2003). Taking intermediation seriously. Journal of Money, Credit, and Banking, 35(6), 1319-1357.

[55] Sprague, O. M. W. (1910). History of crises under the national banking system (Vol. 538). US Government Printing Office.

[56] Williamson, S.D. (2012). Liquidity, Monetary Policy, and the Financial Crisis: A New Monetarist Approach. American Economic Review, 102(6), 2570-2605.

[57] Williamson, S.D. and Wright, R. (2010). New monetarist economics: Models,EHandbook of Monetary Economics, vol. 2, Benjamin M. Friedman and Michael Woodford, eds. North-Holland.

[58] Wallace, N. (1990). A banking model in which partial suspension is best. Federal Reserve Bank of Minneapolis, Quarterly Review, 14 (Fall), 11-23. 